\title{
On the Linearity of the Stratospheric and Euro-Atlantic Sector Response to ENSO $^{\circ}$
}

\author{
Paloma Trascasa-CASTRO AND Amanda C. MAYCOCK \\ School of Earth and Environment, University of Leeds, Leeds, United Kingdom \\ Yu YeUnG SCOTT YiU \\ Department of Chemistry, University of Cambridge, Cambridge, United Kingdom \\ JENNIFER K. FLETCHER \\ School of Earth and Environment, University of Leeds, Leeds, United Kingdom
}

(Manuscript received 1 November 2018, in final form 13 June 2019)

\begin{abstract}
The dependence of the winter stratospheric and Euro-Atlantic climate response on ENSO amplitude is investigated using the HadGEM3 model. Experiments are performed with imposed east Pacific sea surface temperature perturbations corresponding to Niño-3.4 anomalies of $\pm 0.75,1.5,2.25$, and $3.0 \mathrm{~K}$. In the North Pacific, El Niño (EN) deepens and shifts the Aleutian low eastward, while the equivalent magnitude La Niña (LN) perturbations drive anomalies of opposite sign that are around 4 times weaker. The muted North Pacific response to $\mathrm{LN}$ can be traced back to the weaker response of tropical convection and the associated anomalous Rossby wave source. The EN perturbations weaken the Arctic polar vortex, with the winter mean zonal mean zonal wind at $60^{\circ} \mathrm{N}$ and $10 \mathrm{hPa}$ decreasing approximately linearly with Niño-3.4 anomaly by around $-3.6 \mathrm{~m} \mathrm{~s}^{-1} \mathrm{~K}^{-1}$. For the strongest EN case $(+3 \mathrm{~K})$, the frequency of sudden stratospheric warmings (SSWs) increases by $\sim 60 \%$ compared to the control experiment. Hence the results do not support a saturation of the stratospheric pathway for strong EN as suggested in previous literature. The equivalent amplitude LN perturbations cause a weak strengthening of the polar vortex and no substantial change in SSW frequency, in contrast to some reanalysis-based studies. EN induces a negative North Atlantic Oscillation (NAO) index throughout boreal winter, which increases approximately linearly with the Niño-3.4 anomaly by around -0.6 standard deviations $\mathrm{K}^{-1}$. Only the response to the strongest LN perturbations projects onto a weak positive NAO in November, suggesting that the mechanism for the Euro-Atlantic response to LN may be distinct from EN.
\end{abstract}

\section{Introduction}

El Niño-Southern Oscillation (ENSO) is the leading mode of interannual climate variability in the tropics. ENSO has remote influences on climate in many parts of the world (Diaz et al. 2001), offering a potential source of predictive skill on seasonal time scales. This study focuses on the Euro-Atlantic sector, where the surface response to the warm phase of ENSO (El Niño)

\footnotetext{
Supplemental information related to this paper is available at the Journals Online website: https://doi.org/10.1175/JCLI-D-180746.s1.
}

Corresponding author: Paloma Trascasa-Castro, ee17pt@leeds. ac.uk. projects, on average, onto a negative phase of the North Atlantic Oscillation (NAO) (e.g., Li and Lau 2012), with associated impacts on surface wind, temperature, and precipitation patterns (e.g., Ineson and Scaife 2009). The mechanisms for this remote Euro-Atlantic response to El Niño have been extensively studied (e.g., Toniazzo and Scaife 2006; Garfinkel and Hartmann 2008; Bell et al. 2009; Ineson and Scaife 2009; Cagnazzo and Manzini 2009; Butler et al. 2014; Hurwitz et al. 2014; Calvo et al. 2017; Ayarzagüena et al. 2018) and can be broadly categorized as comprising a "tropospheric pathway" (e.g., Toniazzo and Scaife 2006; Bell et al. 2009; JiménezEsteve and Domeisen 2018; Ayarzagüena et al. 2018; Hardiman et al. 2019) and a "stratospheric pathway" (e.g., Bell et al. 2009; Ineson and Scaife 2009; Cagnazzo and Manzini 2009; Garfinkel et al. 2010; Butler and 
Polvani 2011; Butler et al. 2014; Domeisen et al. 2015; Polvani et al. 2017).

Through its effect on precipitation and upper-level divergence in the tropical Pacific, ENSO modulates the generation and propagation of planetary-scale Rossby waves emanating from the tropical Pacific into both hemispheres (Hoskins and Karoly 1981). In the Northern Hemisphere, this is associated with a modulation of the Pacific-North America pattern (PNA), which is a key driver of winter climate variability in North America (Müller and Roeckner 2006). Under El Niño conditions, the Aleutian low deepens relative to ENSO neutral conditions (Niebauer 1988; Rodionov et al. 2005; Bell et al. 2009; Cagnazzo and Manzini 2009), and vice versa for La Niña (Hoerling et al. 1997; Garfinkel et al. 2018). The changes in the Aleutian low under El Niño are associated with an amplification of wavenumber 1 and an increase in upward propagation of wave activity into the Northern Hemisphere high-latitude stratosphere in winter (Rodionov et al. 2005; Ineson and Scaife 2009; Garfinkel et al. 2010; Domeisen et al. 2015).

Momentum deposition by planetary-scale Rossby waves is the dominant driver of intraseasonal variability of the stratospheric polar vortices during winter months; the increased wave forcing in the stratosphere under El Niño weakens the polar vortex and increases the frequency of major sudden stratospheric warmings (SSWs) (Charlton and Polvani 2007; Cagnazzo and Manzini 2009; Ineson and Scaife 2009; Bell et al. 2009; Butler and Polvani 2011; Butler et al. 2014; Domeisen et al. 2015; Scaife et al. 2016). In turn, SSWs can induce a negative NAO index anomaly for up to two months after onset (e.g., Hitchcock and Simpson 2014), leading to an extended influence on European surface climate in winter (e.g., Ineson and Scaife 2009; Cagnazzo and Manzini 2009; Polvani et al. 2017). This chain of mechanisms constitutes the stratospheric pathway for the El Niño teleconnection to the Euro-Atlantic sector. The role of the stratospheric pathway in the response to La Niña is less well understood, although studies have generally found an opposite response with a strengthening of the polar vortex in winter (Manzini et al. 2006; Garfinkel and Hartmann 2008; Iza et al. 2016; Hardiman et al. 2019). Previous studies based on reanalysis and observational data (e.g., Garfinkel and Hartmann 2008; Rao and Ren 2016a) suggest that nonlinearities in the Arctic stratospheric response to El Niño and La Niña can arise from differences in the tropospheric wave forcing during ENSO events. It has been proposed that El Niño enhances the amplitude of wavenumber 1 in the northern high-latitude stratosphere, but has a smaller effect on the amplitude of wavenumber 2 , whereas in La Niña winters the amplitude of wavenumber 2 may increase (Barriopedro and Calvo 2014; Rao and Ren 2016a; Garfinkel et al. 2012). Some reanalysis datasets suggest an increase in the frequency of major SSWs under both El Niño and La Niña conditions (Butler and Polvani 2011), although this result may not be robust across different reanalyses (Polvani et al. 2017). Such a result of increased SSW frequency for both ENSO phases would appear to be inconsistent with the finding from some models of a strengthening of the polar vortex during $\mathrm{La}$ Niña (e.g., Garfinkel et al. 2012; Iza et al. 2016; Hardiman et al. 2019).

There is also a tropospheric pathway for the EuroAtlantic sector response to ENSO, which may become especially relevant in years with no SSW events (e.g., Domeisen et al. 2015). Li and Lau (2012) proposed that changes in the strength of the Aleutian low in the North Pacific during El Niño winters are directly linked to the NAO by enhanced eastward wave activity flux and propagation of transient eddies from the North Pacific to the North Atlantic. For La Niña, an increase in eastward propagation of Rossby waves into the tropical Atlantic is the most effective mechanism for a tropospheric pathway when the polar vortex tends to be strongest (JiménezEsteve and Domeisen 2018), leading to a positive NAO index. Iza et al. (2016) also highlight the role of La Niña as a driver of stratospheric circulation changes in winter only in the absence of SSWs. Toniazzo and Scaife (2006) suggest that for the strongest El Niño events, the EuroAtlantic sector surface climate response has its origin in the tropical Atlantic, and Rodríguez-Fonseca et al. (2016) emphasize the key role of ENSO-driven changes in the Hadley and Walker circulations in the tropical PacificAtlantic teleconnection, consisting of wind regime anomalies that affect the North Atlantic-European sector. Ayarzaguiena et al. (2018) found that a region of anomalous Rossby wave source near the Caribbean Sea was important for the early winter North Atlantic response to both El Niño and La Niña. Building on this finding, Hardiman et al. (2019) used an ensemble of initialized hindcasts from a decadal prediction system and found that the tropospheric pathway via the Caribbean Sea dominated the response in January in strong El Niño years, but that the stratospheric pathway via a strengthening of the polar vortex was most important in strong La Niña years.

Variations in the amplitude and pattern of the EuroAtlantic sector response to ENSO have been attributed to the dominance of different atmospheric pathways (Butler et al. 2014; Domeisen et al. 2015), to different magnitudes of ENSO events (Toniazzo and Scaife 2006; Bell et al. 2009), and to the details of the spatial pattern of sea surface temperature (SST) anomalies in the equatorial Pacific (Calvo et al. 2017; Ayarzagüena et al. 2019). However, the diversity of findings across the literature indicates uncertainty in the relative importance 
of stratospheric and tropospheric pathways for the response of Euro-Atlantic sector climate to ENSO. A common approach to assess remote teleconnections in observations is to composite all El Niño and La Niña events, but the number of ENSO events in the reanalysis era is relatively small (19 El Niño and 18 La Niña events in NCEP-NCAR reanalysis over the period 1958-2013; Butler et al. 2014) and the spatial characteristics and amplitude of individual events vary substantially, which may influence remote effects. Furthermore, internal climate variability in the Euro-Atlantic sector is large (Visbeck et al. 2001; Hurrell et al. 2003), making it difficult to identify the relative importance of specific ENSO characteristics in determining teleconnections to Europe.

This paper aims to systematically explore the relationship between ENSO magnitude and the EuroAtlantic response to ENSO using a set of idealized climate model experiments that impose different amplitude SST anomalies in the tropical east Pacific. The focus of the study will be on the response in boreal winter [December-February (DJF)], as this is the season when the Northern Hemisphere stratosphere is dynamically active.

The remainder of the paper is laid out as follows: section 2 describes the model setup and analysis methods, results are presented in section 3, and a discussion in light of previous literature in section 4. Finally, our conclusions are given in section 5 .

\section{Methods}

Experiments were performed with the Met Office Hadley Centre Global Environment Model version 3 (HadGEM3) based on the Unified Model (UM) version 8.4. The model was run in an atmosphere-only configuration at $\mathrm{N} 96$ horizontal resolution $\left(1.875^{\circ}\right.$ longitude $\times$ $1.25^{\circ}$ latitude) and with 85 vertical levels from the surface up to an altitude of $\sim 84 \mathrm{~km}$ (Mizielinski et al. 2014). Earlier generations of the HadGEM model have been shown to capture the mean climatology and variability of the Northern Hemisphere stratosphere in winter (e.g., Hardiman et al. 2012; Osprey et al. 2013; Charlton-Perez et al. 2013), which is important for the ENSO teleconnection to the Euro-Atlantic sector (Ineson and Scaife 2009).

Monthly SSTs and sea ice are imposed from the HadISST dataset (Rayner et al. 2003), with the control simulation using a climatology averaged over 1995-2005 to represent approximate ENSO neutral conditions. All other forcings (e.g., the concentrations of well-mixed greenhouse gases) are fixed at year 2000 levels in all experiments. The experiments are time slice simulations integrated for 54 years with an annual cycle but no interannual variation in boundary conditions. The perturbation experiments impose SST anomalies in the tropical east Pacific to represent an ENSO-like anomaly. The functional form of the imposed SST perturbations $(\Delta T)$ is

$$
\Delta T(\lambda, \varphi)= \begin{cases}\alpha \times \arctan \left(\frac{\lambda-180}{6}\right) \times \exp \left[-0.03\left(\varphi^{2}\right)\right], & \text { if } 180^{\circ} \leq \lambda \leq 285^{\circ} \\ 0, & \text { otherwise } \quad-10^{\circ} \leq \varphi \leq 10^{\circ} \\ & \text { and }\end{cases}
$$

where the constant $\alpha$ is set to $\pm 0.58, \pm 1.15, \pm 1.73$, and \pm 2.3 . This function creates SST anomalies corresponding to eight different ENSO amplitudes, with associated El Niño-like and La Niña-like SST anomalies in the Niño-3.4 region $\left(5^{\circ} \mathrm{N}-5^{\circ} \mathrm{S}, 190^{\circ}-240^{\circ} \mathrm{E}\right)$ of $-3.0 \mathrm{~K}(\mathrm{LN} 3),-2.25 \mathrm{~K}(\mathrm{LN} 2.25),-1.5 \mathrm{~K}(\mathrm{LN} 1.5)$, $-0.75 \mathrm{~K}(\mathrm{LN} 0.75),+0.75 \mathrm{~K}(\mathrm{EN} 0.75),+1.5 \mathrm{~K}(\mathrm{EN} 1.5)$, $+2.25 \mathrm{~K}(\mathrm{EN} 2.25)$, and $+3.0 \mathrm{~K}(\mathrm{EN} 3)$. In the longitudinal direction, the SST anomalies increase rapidly in amplitude from $180^{\circ}$ to $200^{\circ} \mathrm{E}$, reaching $\sim 75 \%$ of the full amplitude by $200^{\circ} \mathrm{E}$, and increasing more gradually thereafter to a maximum in the east Pacific. The function decays exponentially with latitude away from the equator reaching zero at $\pm 10^{\circ}$. The SST anomaly pattern is not designed to represent a specific real-world ENSO, but rather aims to capture the broad canonical pattern of SSTs associated with ENSO events.
To characterize the degree of similarity of the imposed SST perturbations to observed ENSO, Fig. 1 shows composite El Niño and La Niña SST anomalies derived from ERA-Interim (Dee et al. 2011). The composites are based on a threshold oceanic Niño index in DJF of $\pm 0.5 \mathrm{~K}$, which identifies 13 El Niños (1980, 1983, 1987, 1988, 1992, 1995, 1998, 2003, 2005, 2007, 2010, 2015, and 2016) and 13 La Niñas (1984, 1985, 1989, 1996, 1999, 2000, 2001, 2006, 2008, 2009, 2011, 2012, and 2018) over the period 1980-2018. The SST anomaly imposed in the model is shown for the EN0.75 case in Fig. 1c. The pattern correlation of the imposed SST anomaly over the region $180^{\circ}-270^{\circ} \mathrm{E}, 10^{\circ} \mathrm{N}-10^{\circ} \mathrm{S}$ with the observed El Niño and La Niña composites is 0.76 and 0.66, respectively. With individual observed ENSOs it ranges from -0.48 (2015) to 0.83 (2016) for El Niño, and from -0.38 (2011) to 0.85 (1985) for La Niña, owing to 
a)

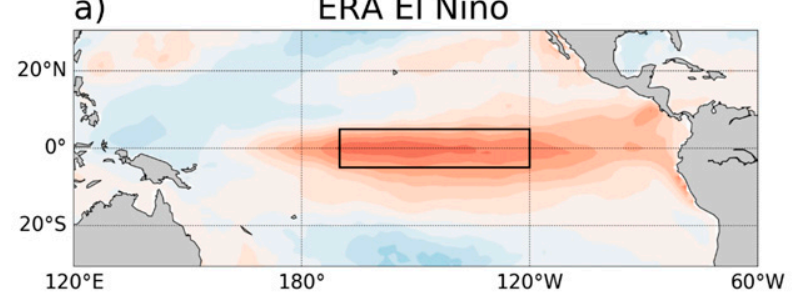

b)

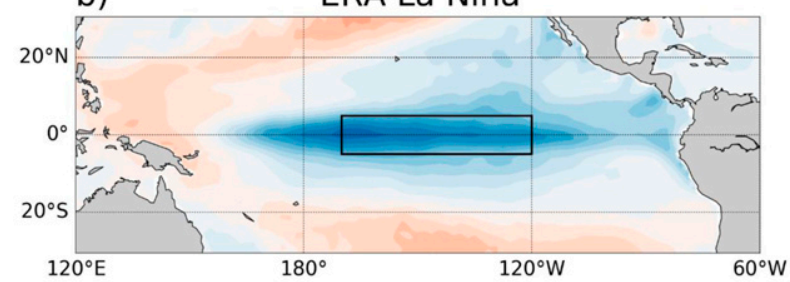

c)

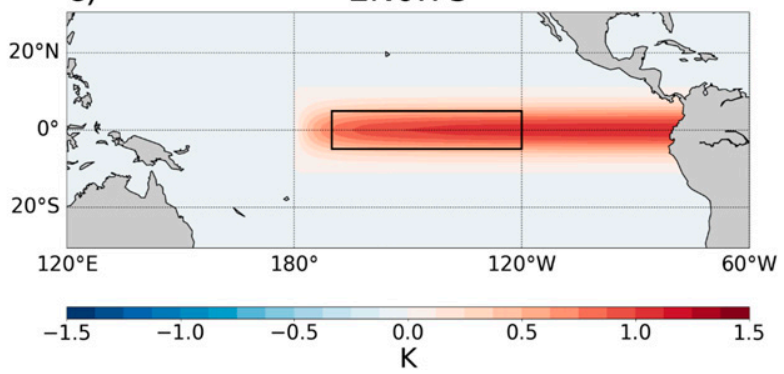

FIG. 1. Composite SST anomalies (K) for (a) El Niño and (b) La Niña events identified over 1980-2018 using the SST dataset from ERA-Interim, plotted alongside (c) the imposed $0.75 \mathrm{~K}$ El Niño perturbation from our experiments.

the large interevent variation in ENSO characteristics (Capotondi et al. 2015). Hence, although the imposed SST anomaly has a slightly lower pattern correlation with the observed La Niña composite compared to El Niño, there are individual events for both phases where the imposed anomaly resembles observations similarly well.

Note that even in the case of there being similar SST patterns for El Niño and La Niña, nonlinearities in the tropical response could occur owing to the threshold behavior of convection with SST (Graham and Barnett 1987; Waliser and Graham 1993; Zhang 1993) and the presence of the SST cold tongue in the east Pacific (e.g., Johnson and Kosaka 2016; Xie et al. 2018). As a consequence, the spatial pattern of SST, as well as its amplitude, is likely to be important for understanding differences in teleconnections between ENSO events (Calvo et al. 2017; Larkin and Harrison 2005; Ayarzagüena et al. 2019). However, according to the model study of Garfinkel et al. (2018), at least 75 central and east Pacific type events are required to distinguish significant differences in the North Pacific response to El Niño flavors, and hence we restrict the focus of this study to examining the effect of varying ENSO amplitude for a fixed SST pattern.

In each of the HadGEM3 perturbation experiments the SST anomalies are held fixed throughout the 54-yr integrations, thereby simulating perpetual ENSO conditions throughout the year. Although idealized in nature, the experimental design enables a systematic investigation of the effect of different ENSO magnitudes and offers a significantly larger sample size than available in the observational record. This is important when considering the large internal variability in both the Arctic winter stratosphere (Maycock and Hitchcock 2015) and the Euro-Atlantic sector in the troposphere, and therefore provides a more robust sample in comparison to some previous literature.

The analysis focuses on the Northern Hemisphere response to ENSO in boreal winter. Analysis of the Southern Hemisphere teleconnection response in a subset of the experiments shown here can be found in Yiu and Maycock (2019). A two-tailed Student's $t$ test is used to assess the significance of the simulated changes between the perturbation and control experiments using a threshold of $95 \%$ confidence level. Major SSWs are identified following Charlton and Polvani (2007), and the station-based NAO index is calculated following Hurrell (1995) as the difference in normalized sea level pressure (SLP) between Ponta Delgada (Azores) and Reykjavik (Iceland) averaged over the winter months (DJF). To calculate the regional surface climate response to the imposed ENSO perturbations, two geographic regions are defined: Northern Europe (NEU) covers all land and sea points between $48^{\circ}-75^{\circ} \mathrm{N}$ and $10^{\circ} \mathrm{W}-40^{\circ} \mathrm{E}$; the Mediterranean basin (MED) represents the southern European response and is delimited by $30^{\circ}-48^{\circ} \mathrm{N}$ and $10^{\circ} \mathrm{W}-40^{\circ} \mathrm{E}$ (Giorgi and Francisco 2000 ).

\section{Results}

\section{a. North Pacific response}

To quantify changes in the strength and position of the Aleutian low, Fig. 2 shows 500-hPa geopotential height (Z500) anomalies over the North Pacific in the eight ENSO perturbation experiments. El Niño forcing (Figs. 2a-d) causes a decrease in Z500 over the North Pacific and an eastward shift of the center of the Aleutian low toward the west coast of North America. This broad pattern of response to El Niño is consistent with most previous studies (e.g., Niebauer 1988; Müller and Roeckner 2006; Ineson and Scaife 2009). The peak magnitude of the North Pacific Z500 response near the center of the Aleutian low $\left(40^{\circ} \mathrm{N}, 205^{\circ} \mathrm{E}\right.$ in the model) increases monotonically with El Niño amplitude. 
(a) EN0.75 - CTRL

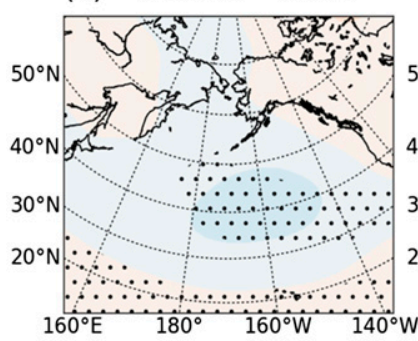

(b) EN1.5 - CTRL

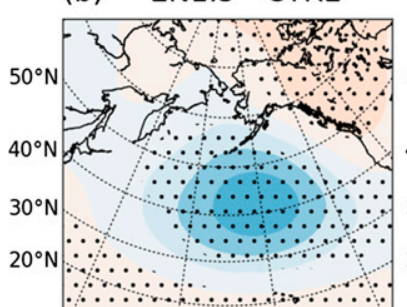

(c) EN2.25 - CTRL (d) EN3 - CTRL

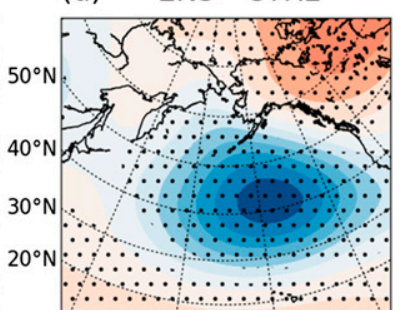

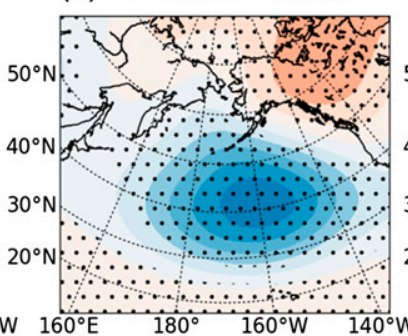

$160^{\circ} \mathrm{E} \because 180^{\circ} \frac{160^{\circ} \mathrm{W}}{140^{\circ} \mathrm{W}}$

$-200-150-100-50 \quad 0 \quad 50 \quad 100150200$

(e) LN0.75 - CTRL

(f) LN1.5 - CTRL

$\mathrm{m}$
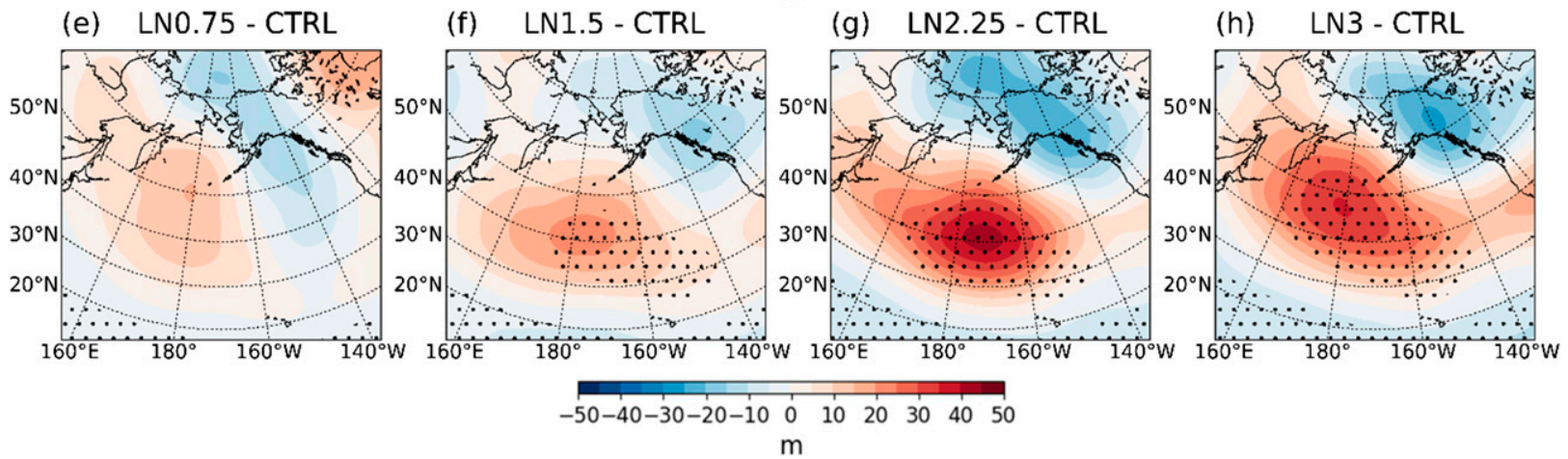

FIG. 2. DJF geopotential height response at $500 \mathrm{hPa}(\mathrm{m})$ in the North Pacific to the eight different magnitude ENSO events: (a) EN0.75, (b) EN1.5, (c) EN2.25, (d) EN3, (e) LN0.75, (f) LN1.5, (g) LN2.25, and (h) LN3. Red colors indicate positive anomalies and blue colors indicate negative anomalies. Black stippling denotes statistical significance at the $95 \%$ confidence level. Note the different scaling between top and bottom row plots.

Conversely, the imposed La Niña perturbations (Figs. 2e-h) induce positive Z500 anomalies in the North Pacific sector; however, these are weaker than in the equivalent El Niño experiments and in the case of LN0.75 are indistinguishable from internal variability. Comparing equivalent amplitude EN and LN cases in Fig. 2, the peak North Pacific Z500 response in EN2.25 (EN3) is 3.4 (4.7) times larger than for the equivalent $\mathrm{LN}$ case. In EN1.5 the peak Z500 response is around 2.6 times larger than in EN0.75 and around 1.8 times smaller than in EN3.

To further examine the asymmetry in the North Pacific response between the El Niño and La Niña experiments, Fig. 3a shows the sum of the SLP responses in EN1.5 and LN1.5 multiplied by a factor of 2 for comparison with the sum of the EN3 and LN3 responses shown in Fig. 3b. In the North Pacific, there is a strongly asymmetric response between El Niño and La Niña of up to $15 \mathrm{hPa}$, which is similar for both $2 \times(\mathrm{EN} 1.5+\mathrm{LN} 1.5)$ and EN3 + LN3; this confirms the larger impact of El Niño on the Aleutian low in our experiments. Based on an area-averaged North Pacific SLP index $\left(35^{\circ}-60^{\circ} \mathrm{N}\right.$, $180^{\circ}-240^{\circ} \mathrm{E}$ ), the response in LN2.25 and LN3 is around 6 times smaller than the equivalent EN experiment (see Fig. S1 in the online supplemental material). Some previous literature suggests that although opposite in sign, the amplitude of the North Pacific responses are similar for El Niño and La Niña (Garfinkel et al. 2012; Polvani et al. 2017). However, Rao and Ren (2016b) found a saturation of the North Pacific response under strong La Niña forcing, although the magnitudes of their SST anomalies for moderate $(-1 \mathrm{~K})$ and strong $(-2 \mathrm{~K})$ La Niñas are smaller than our LN2.25 and LN3 experiments. Jiménez-Esteve and Domeisen (2019) also find a nonlinear North Pacific SLP response between El Niño and La Niña in DJF, with the response to moderate El Niño $(1.5 \mathrm{~K})$ being around 1.5 times larger than for moderate La Niña, and the response to strong El Niño (3K) around 3 times larger than for strong La Niña (see their Fig. 3c). The area-average North Pacific SLP response in our LN3 experiment $(-1.4 \mathrm{hPa})$ is around a factor of 2 smaller than the $-3 \mathrm{~K}$ La Niña case of Jiménez-Esteve and Domeisen (2019). Note, however, that caution should be taken when comparing area-average anomalies, as the patterns of response to EN and LN in the North Pacific are somewhat different, with the maximum anomalies being generally located farther west in the LN experiments compared to the equivalent amplitude EN case (Fig. 2).

We now examine the degree of nonlinearity in response to moderate and strong events within El Niño and La Niña phases. Figure $3 \mathrm{c}$ shows the difference in responses of EN3 - $(2 \times$ EN1.5) and Fig. 3d shows 
(a) $2 \times($ EN15 + LN15)

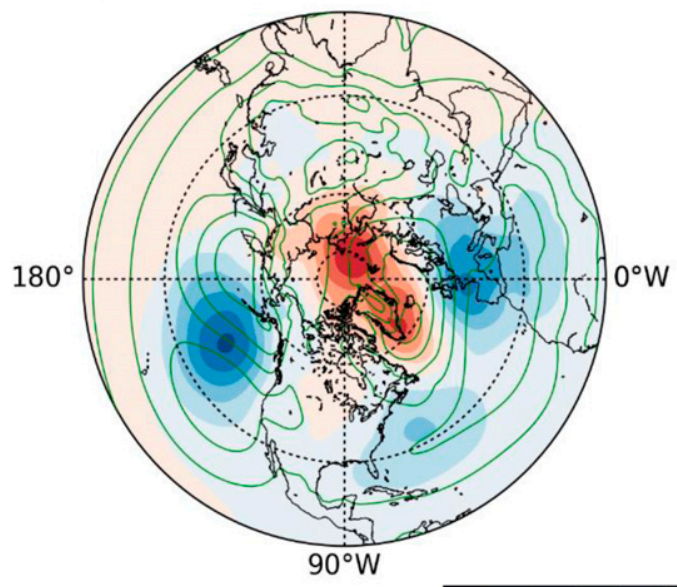

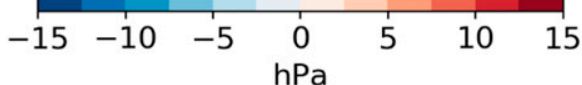

(b) $\quad \mathrm{EN} 3+\mathrm{LN} 3$

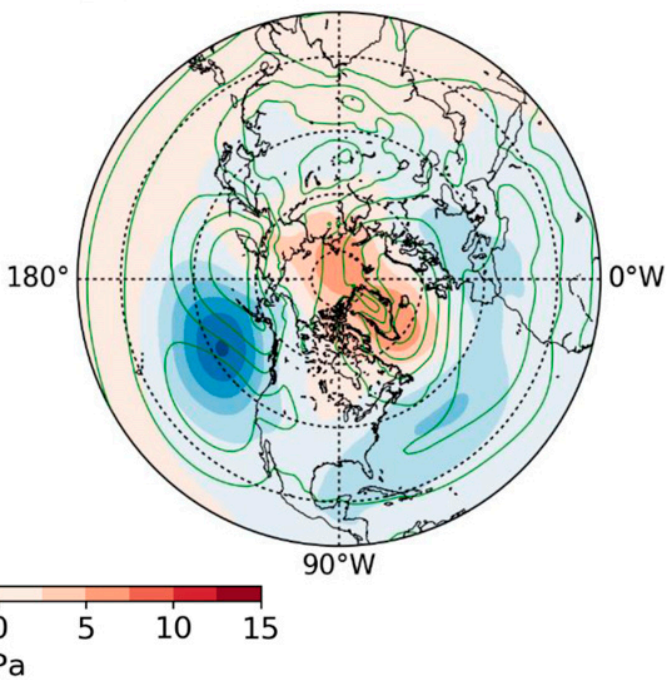

(d) LN3 - 2xLN15

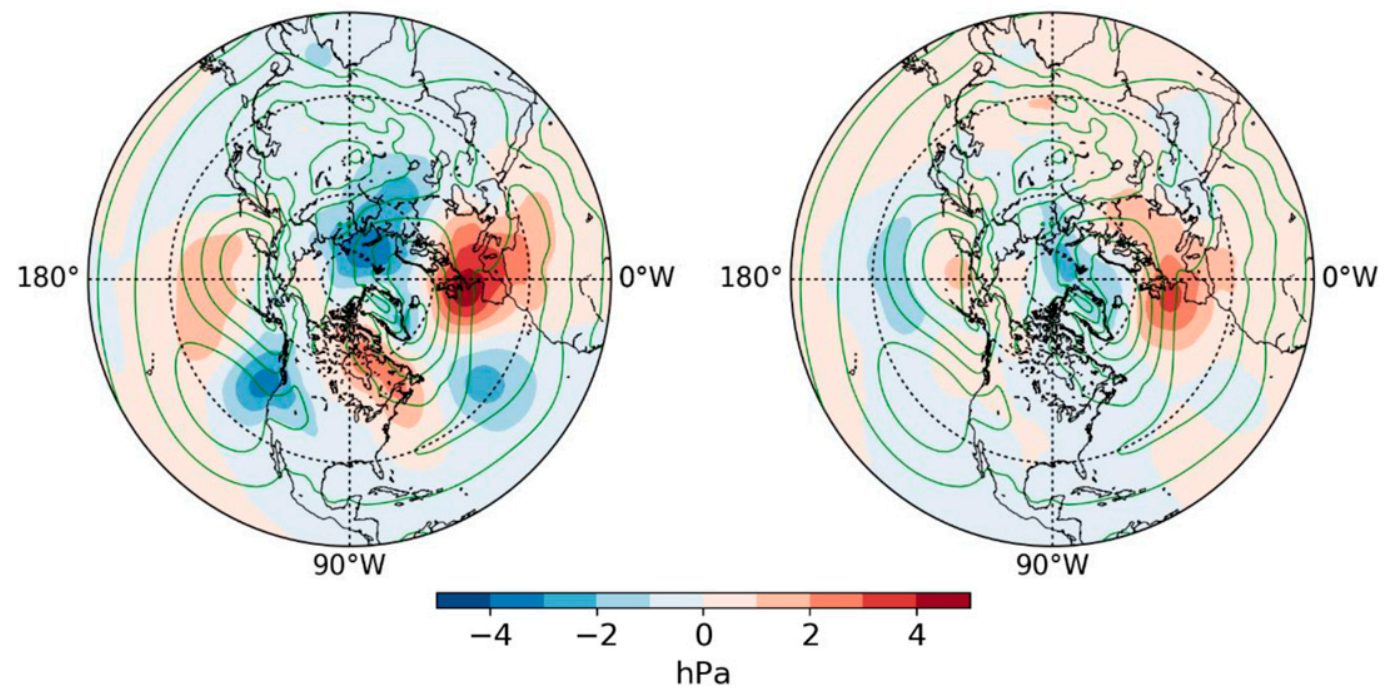

FIG. 3. Northern Hemisphere SLP response asymmetry (hPa) in (a) twice a $\pm 1.5 \mathrm{~K}$ forcing (EN15 and LN15) and (b) strong ENSO forcings (EN3 and LN3) following Jiménez-Esteve and Domeisen (2019). (bottom) Nonlinearity in the SLP response to (c) El Niño and (d) La Niña, calculated by subtracting twice a moderate event $( \pm 1.5 \mathrm{~K})$ from the strongest ENSO amplitude $( \pm 3 \mathrm{~K})$. Green contours show climatological signal; intervals are $5 \mathrm{hPa}$.

LN3 - $(2 \times$ LN1.5 $)$. Note that the scale of the interphase asymmetry plots (Figs. 3a,b) is 3 times larger than the scale on the intraphase nonlinearity (Figs. 3c,d) plots, indicating that the magnitude of the SLP response in the experiments is more nonlinear between the warm and cold phases of ENSO than across different amplitudes of the same phase. Figure $3 \mathrm{c}$ shows a nonlinear response in the North Pacific between EN1.5 and EN3, with a relatively stronger deepening of the Aleutian low between EN1.5 and the control than between EN1.5 and EN3. Using the area-averaged SLP measure, we find an
Aleutian low response of $-1.4,-3.9,-7.0$, and $-8.5 \mathrm{hPa}$ for EN0.75, 1.5, 2.25, and $3 \mathrm{~K}$, respectively (see Fig. S1). The relative decreases in North Pacific SLP for successive $0.75 \mathrm{~K}$ El Niño increments between 0 and $3 \mathrm{~K}$ are therefore $1.4,2.5,3.1$, and $1.5 \mathrm{hPa}$. These correspond to increases in the amplitude of the SLP response by a factor of 2.8 and 2.2 for successive doublings from 0.75 to $1.5 \mathrm{~K}$ and 1.5 to $3 \mathrm{~K}$, respectively. However, for EN2.25 the mean SLP response is around $65 \%$ larger than for $3 \times \mathrm{EN} 0.75$. Jiménez-Esteve and Domeisen (2019) find based on the same SLP measure for the Aleutian low that the DJF response to strong 
(a)

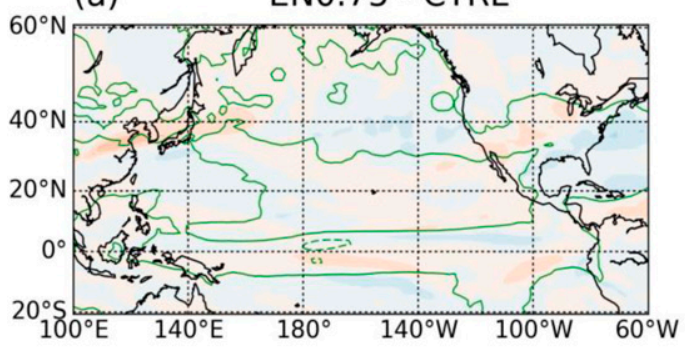

(c)

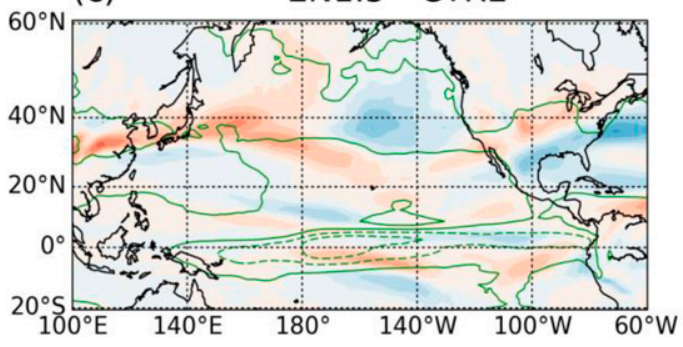

(e)

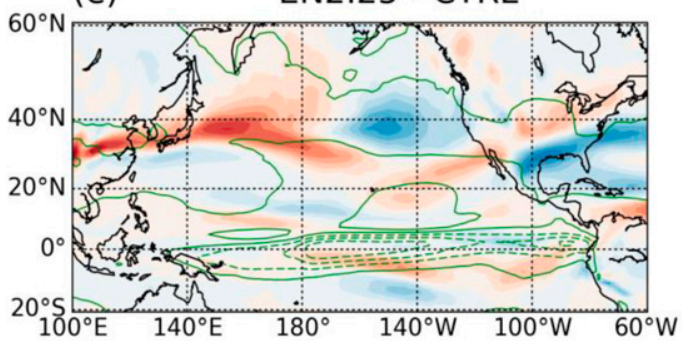

(g)

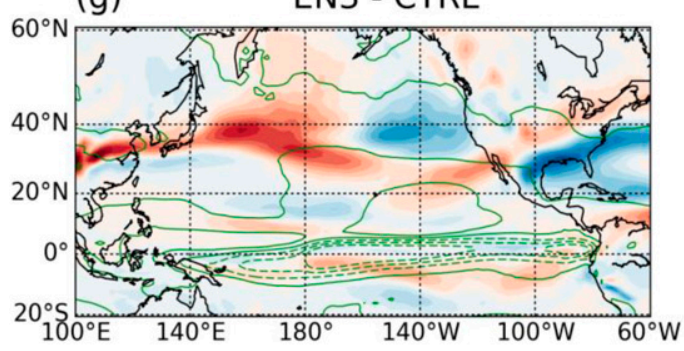

(b)

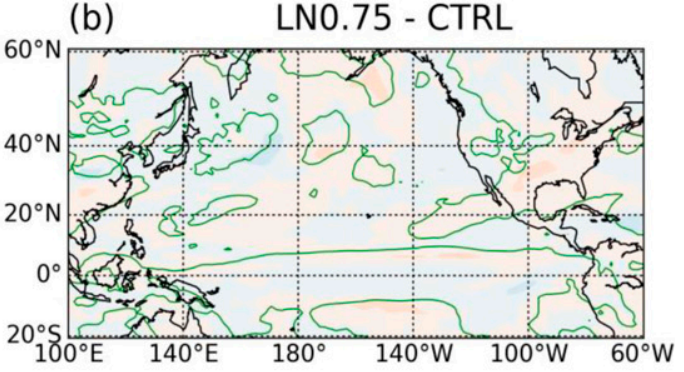

(d)

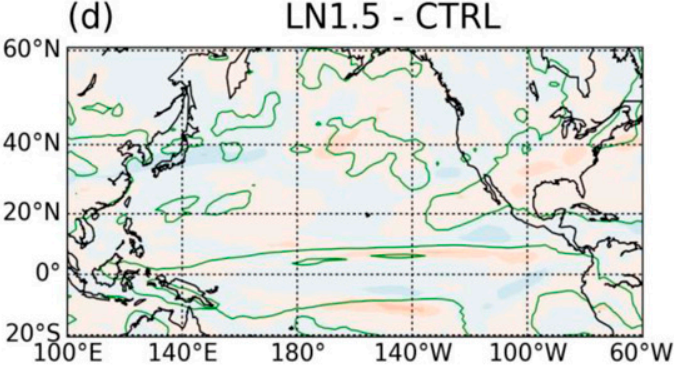

(f)

LN2.25 - CTRL

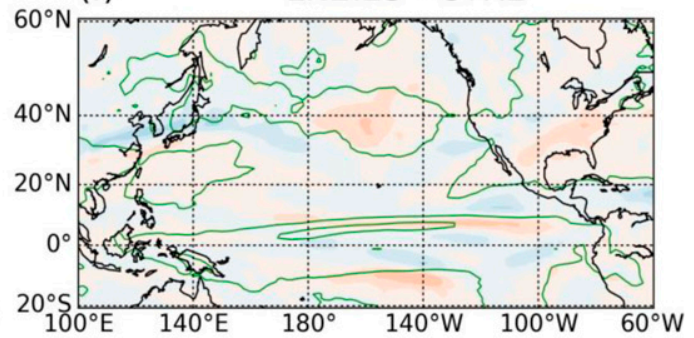

(h)

LN3 - CTRL

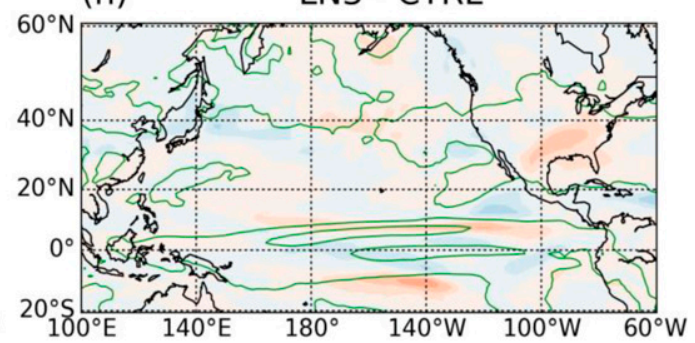

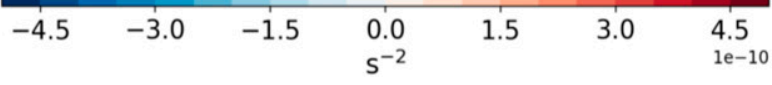

FIG. 4. DJF $200 \mathrm{hPa}$ Rossby wave source $\left(\mathrm{s}^{-2}\right)$ anomalies following Sardeshmukh and Hoskins (1988) for (left) El Niño and (right) La Niña perturbations. Green contours show positive (solid line) and negative (dashed line) anomalies in outgoing longwave radiation; the contour interval is $\pm 30 \mathrm{~W} \mathrm{~m}^{-2}$.

El Niño forcing $(+3 \mathrm{~K})$ is around a factor of 2.5 to 3 larger than for moderate $(+1.5 \mathrm{~K})$ forcing.

\section{b. Tropical response}

The differences in the North Pacific response between El Niño and La Niña can be traced back to the response of convection in the tropical Pacific and the associated
Rossby wave source (RWS) anomalies (Fig. 4). The anomalies in outgoing longwave radiation (OLR) show a weaker tropical circulation response to La Niña compared to El Niño. Despite the idealized nature of the imposed SST anomalies, the relationship between OLR and SST in the tropical east Pacific $\left(5^{\circ} \mathrm{S}-5^{\circ} \mathrm{N}, 190^{\circ}-240^{\circ} \mathrm{E}\right)$ compares well with observations [see our Fig. S2 in the online 
supplemental material; also, see Fig. 2c of Johnson and Kosaka (2016)]. As a consequence of the weaker convection response, the RWS anomalies, which peak around the location of the subtropical westerly wind maximum (Sardeshmukh and Hoskins 1988), are around 4 times weaker in the $\mathrm{LN}$ experiments compared to the EN cases. El Niño drives a negative RWS anomaly in the eastern margin of the North Pacific at approximately $40^{\circ} \mathrm{N}$ and a positive RWS anomaly in the northwest Pacific, both of which increase with the magnitude of the El Niño forcing.

The weak response of convection in the tropical $\mathrm{Pa}$ cific to La Niña is consistent with the findings of Xie et al. (2018), who showed that the cold tongue in the east Pacific makes convection relatively insensitive to cold anomalies because sea surface temperatures fall below the critical threshold for convection (Graham and Barnett 1987; Waliser and Graham 1993; Zhang 1993). This is qualitatively similar to the asymmetry in the convective response to strong El Niño and La Niña events found by Rao and Ren (2016a,b) and Jiménez-Esteve and Domeisen (2019). Xie et al. (2018) artificially increased the background temperatures in the equatorial Pacific to $28^{\circ} \mathrm{C}$ and showed that convection in the tropical Pacific became more sensitive to La Niña perturbations (see also Bayr et al. 2019). It is possible that the particular pattern of imposed SST anomalies used in this study (Fig. 1), which maximizes in the east Pacific, means the simulated response of tropical convection in the La Niña experiments is weaker than might occur for cold events that peak in the west Pacific (e.g., Capotondi et al. 2015).

\section{c. Stratospheric circulation}

Figure 5 shows zonal mean zonal wind anomalies in DJF as a function of latitude and pressure in the different ENSO perturbation experiments. El Niño perturbations drive progressively stronger stratospheric wind anomalies. While in EN0.75 there are only small regions in the lower stratosphere with statistically significant increases in zonal mean zonal wind, the response in EN3 is much larger and reaches $-18 \mathrm{~m} \mathrm{~s}^{-1}$ at $65^{\circ} \mathrm{N}$. The weakening of the polar vortex under El Niño agrees with earlier studies (Taguchi and Hartmann 2005; Toniazzo and Scaife 2006; Cagnazzo and Manzini 2009; Ineson and Scaife 2009; Bell et al. 2009), but here we show the increase in amplitude of the stratospheric wind response to successively larger El Niño forcing. For only the strongest La Niña perturbations (LN2.25 and LN3) is there a small strengthening of the polar vortex in the extratropical lower stratosphere by up to $6 \mathrm{~m} \mathrm{~s}^{-1}$. The strengthening of westerly winds in the troposphere between $10^{\circ}$ and $40^{\circ} \mathrm{N}$ and the weakening of westerlies between $40^{\circ}$ and $70^{\circ} \mathrm{N}$ in Figs. 5a, 5c, 5e, and $5 \mathrm{~g}$ indicate an equatorward shift of the midlatitude eddy-driven jet under El Niño (Ineson and Scaife 2009; Cagnazzo and Manzini 2009; Bell et al. 2009), and vice versa for the La Niña cases.

To elucidate the origin of the differences in the polar vortex response across the ENSO experiments, Fig. 6 shows the anomalous Eliassen-Palm (EP) flux vectors [scaled following Edmon et al. (1980)] and EP flux divergence in DJF. El Niño drives enhanced convergence of EP flux in the stratosphere between $40^{\circ}$ and $80^{\circ} \mathrm{N}$ and 100 to $5 \mathrm{hPa}$. These anomalies increase with the magnitude of El Niño and are accompanied by enhanced upward propagation of wave activity in the lower stratosphere. In contrast, the La Niña perturbations induce substantially weaker EP flux anomalies, with a weak increase in EP flux divergence in the stratosphere and decrease in upward propagation of wave activity that is only clearly evident for LN2.25 and LN3. The differences in upward wave propagation explain the resulting stratospheric responses. The enhanced upward wave propagation in the El Niño experiments is associated with an increase in wavenumber- 1 and a decrease in wavenumber-2 amplitudes (see Fig. S3). For La Niña there is a substantially smaller decrease in wavenumber-1 amplitude compared to the increase found for El Niño, as well as a change in phase rather than amplitude for wavenumber-2 in the strongest La Niña cases (LN2.25 and LN3) (see Fig. S3).

Figure 7 shows the distributions of DJF zonal mean zonal wind anomalies at $10 \mathrm{hPa}$ and $60^{\circ} \mathrm{N}$ for all years in the experiments. Under increasing El Niño forcing there is a systematic shift in the distribution of stratospheric zonal winds to more negative anomalies at an average rate of around $-3.6 \mathrm{~m} \mathrm{~s}^{-1} \mathrm{~K}^{-1}$. This indicates there is not a saturation of the stratospheric response to increasing El Niño forcing in these experiments, contrary to some earlier studies that find a saturation of the stratospheric pathway for strong El Niños (Toniazzo and Scaife 2006; Bell et al. 2009).

The finding from our experiments of an approximately linear response of stratospheric winds is broadly consistent with the results of Weinberger et al. (2019) using a large ensemble of historical simulations from a different climate model, and agrees with the WACCM4 model simulations of moderate and extreme El Niño events found in Zhou et al. (2018). The large-amplitude El Niño imposed by Bell et al. (2009) was based on a composite SST anomaly from four observed El Niños (1982/83, 1986/87, 1991/92, and 1996/97) that was then doubled. Based on the observed Niño-3.4 index for those years, we calculate the magnitude of their double El Niño perturbation likely exceeds the maximum perturbation considered here of $3 \mathrm{~K}$, so it is possible that saturation of the stratospheric pathway may occur at 
(a) EN0.75 - CTRL

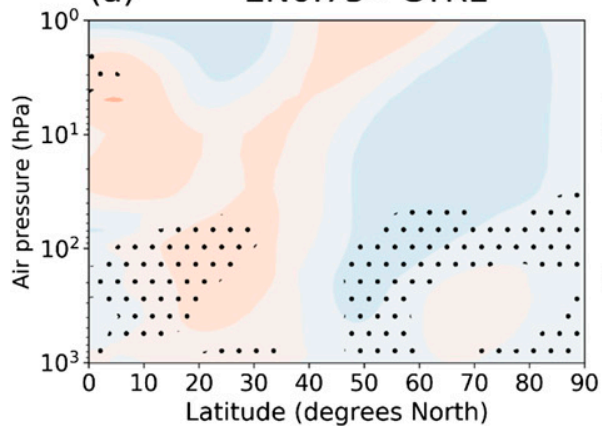

(c) EN1.5 - CTRL

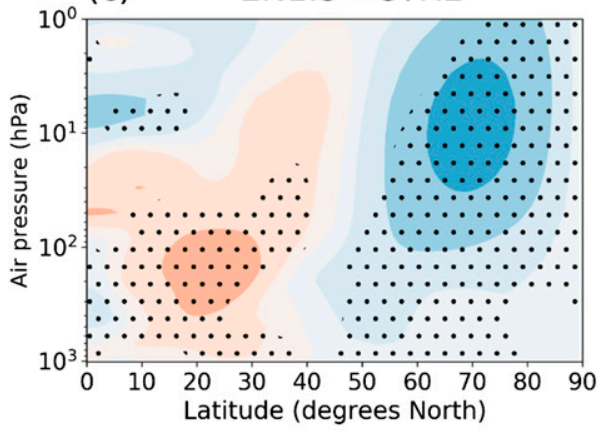

(e) $\quad$ EN2.25 - CTRL
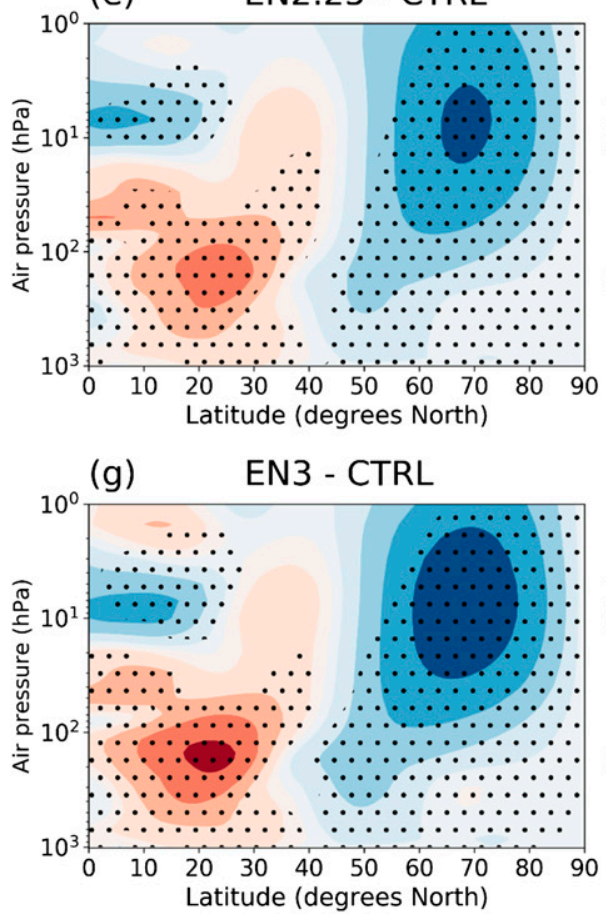

(b) LN0.75- CTRL

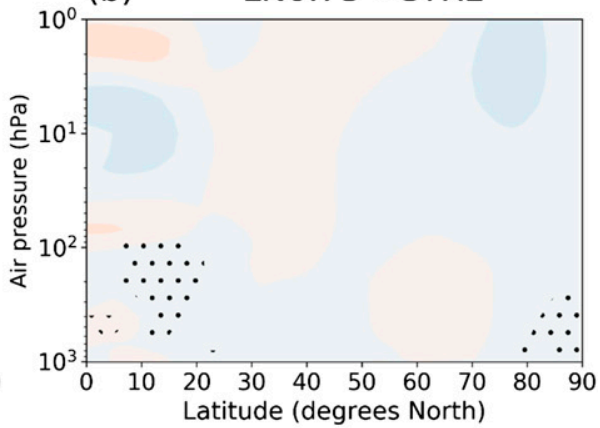

(d) $\quad$ LN1.5 - CTRL

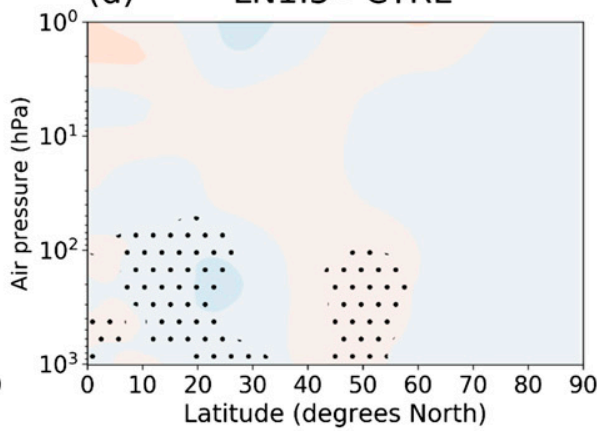

(f) $\quad$ LN2.25 - CTRL

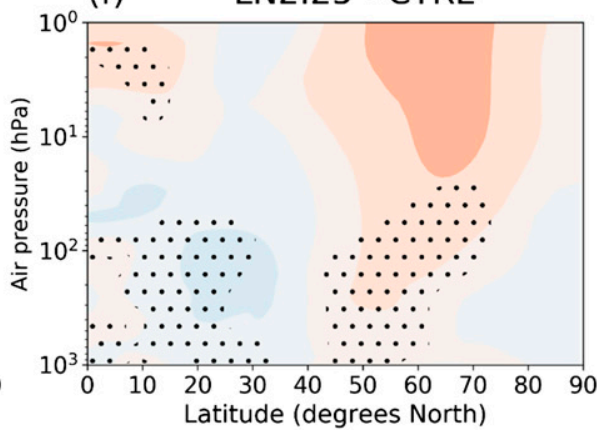

(h) LN3 - CTRL

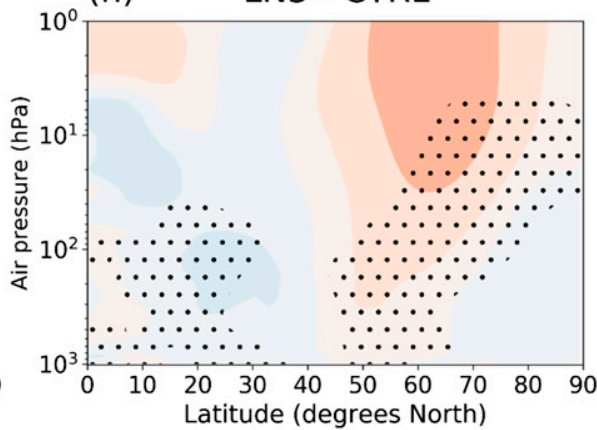

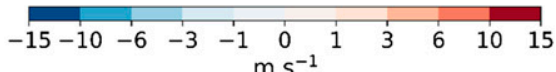

FIG. 5. DJF cross sections of zonal mean zonal wind anomalies $\left(\mathrm{m} \mathrm{s}^{-1}\right)$ in the Northern Hemisphere as a function of pressure and latitude. Zonal mean zonal wind response to (left) El Niño and (right) La Niña in (from top to bottom) crescent order of magnitude. Red (blue) colors show positive (negative) anomalies in zonal mean zonal wind. Pressure is assumed to decrease logarithmically. Black stippling indicates statistical significance at the $95 \%$ confidence level. 

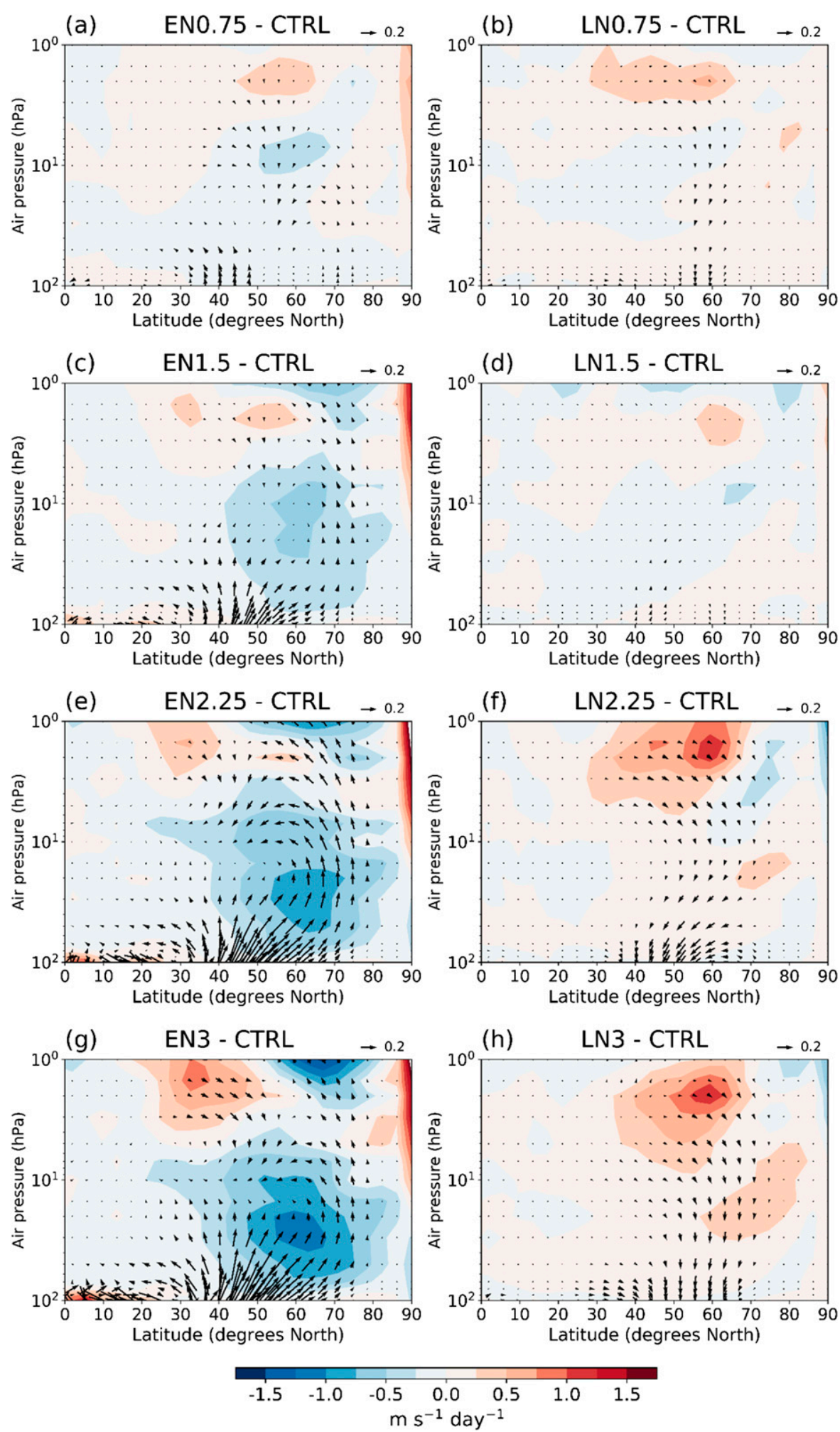

FIG. 6. DJF anomalous Eliassen-Palm flux vectors and EP flux divergence (shading) $\left(\mathrm{m} \mathrm{s}^{-1} \mathrm{day}^{-1}\right)$ in the Northern Hemisphere stratosphere for the ENSO experiments. The vectors are scaled following Edmon et al. (1980). 


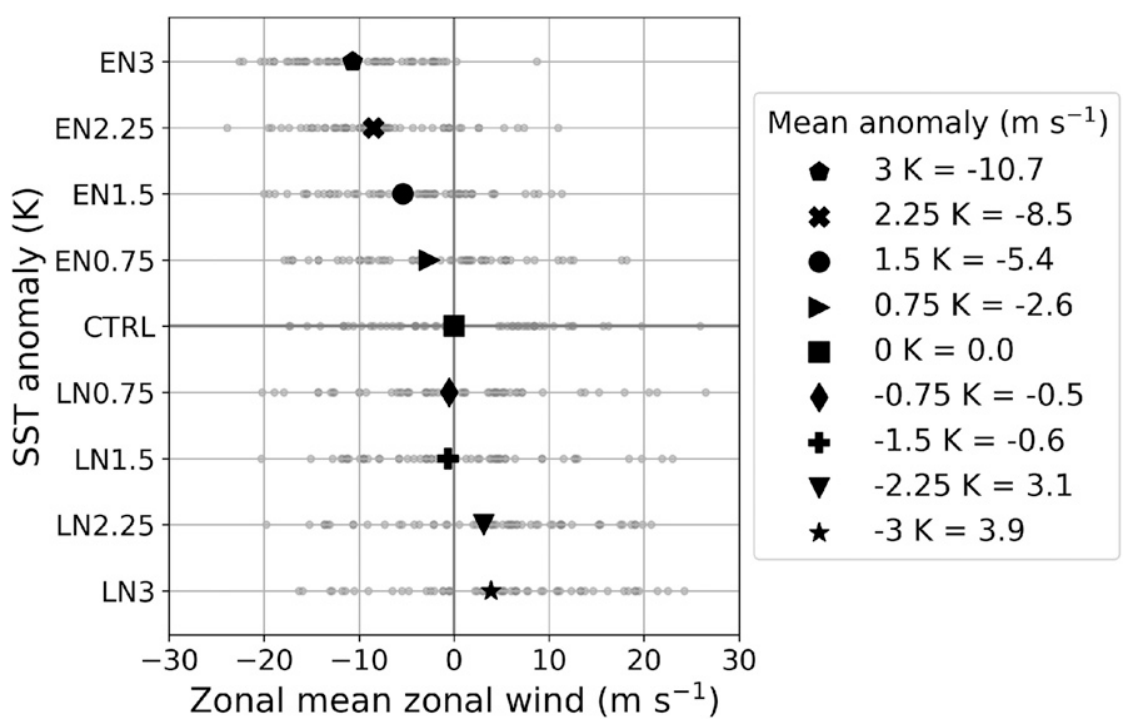

FIG. 7. Scatterplot of DJF zonal mean zonal wind anomalies $\left(\mathrm{m} \mathrm{s}^{-1}\right)$ at $60^{\circ} \mathrm{N}$ and $10 \mathrm{hPa}$ as a function of ENSO amplitude. Each gray point represents one year and the black symbols show the 54-yr mean anomaly for each experiment.

even larger El Niño forcing, but this would be stronger than observed El Niños since preindustrial times.

In the La Niña experiments, Fig. 7 shows that detectible zonal mean zonal wind anomalies at $10 \mathrm{hPa}$ and $60^{\circ} \mathrm{N}$ only occur for LN2.25 and LN3. There is a strong correlation $(r=0.97)$ across all the experiments between the mean change in DJF Aleutian low SLP index (see Fig. S1) and the mean change in DJF zonal mean zonal wind at $10 \mathrm{hPa}$ and $60^{\circ} \mathrm{N}$, indicating the importance of the North Pacific response for the changes to upward wave propagation as discussed above.

As described in the introduction, the changes in polar vortex strength during ENSO have been linked to changes in the frequency of SSWs. Figure 8 shows the frequency of major SSWs by month in the model experiments. The control experiment has an average SSW frequency of $\sim 0.8 \mathrm{yr}^{-1}$, which is slightly higher than the frequency of SSWs under ENSO neutral conditions derived from reanalyses $\left(\sim 0.4-0.6 \mathrm{yr}^{-1}\right.$; Butler et al. 2014). The La Niña experiments show a small decrease in mean SSW frequency of between 0.05 and $0.12 \mathrm{yr}^{-1}$, but these changes are small compared to the large interannual variability. There is also no substantial change in SSW frequency in the EN0.75 experiment. However, in the EN1.5, EN2.25, and EN3 experiments the frequency of SSWs increases by $0.28,0.45$, and $0.49 \mathrm{yr}^{-1}$ $(35 \%, 57 \%$, and $62 \%)$, respectively. The majority of the additional SSWs occur in January and February, whereas there is a relative decrease in March warmings.

Figure 8 shows that the weakening of the polar vortex in midwinter (DJF) in the El Niño experiments (Figs. 5 and 7) occurs alongside an increase in frequency of SSWs. The relative increase in SSW frequency is largest from EN1.5 to EN2.25, while the increase between EN2.25 and EN3 is smaller. While this could suggest onset of a saturation of the stratospheric response to El Niño, where the number of SSWs that can occur in a given year is limited by their characteristic dynamical time scales (Bell et al. 2009), the mean zonal wind anomalies (Fig. 7) show a proportionately larger increase in response from EN2.25 to EN3. This could indicate that the SSWs that occur in EN3 have either larger amplitude or persist for longer, or that the seasonal mean stratospheric zonal wind anomalies are not strongly related to SSW frequency (Garfinkel et al. 2012).

Across all the El Niño experiments, the average increase in SSW frequency is $37 \%$. In contrast, there is a

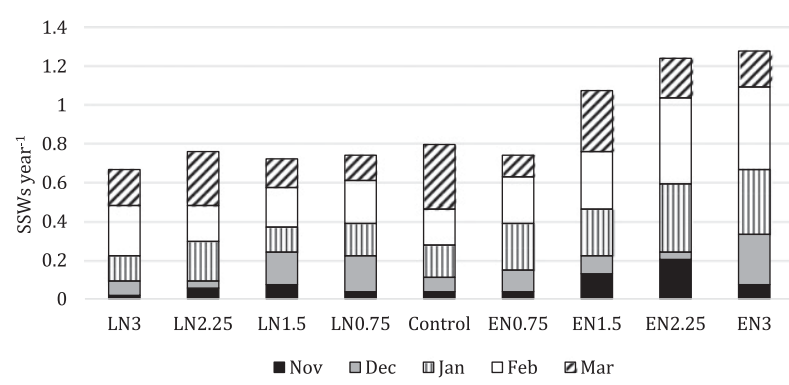

FIG. 8. Frequency of major sudden stratospheric warmings $\left(S S W s r^{-1}\right)$ sorted by month in the ENSO perturbation experiments. SSWs are identified following Charlton and Polvani (2007). November is shown in black, December in gray, January with vertical lines, February in white, and March with diagonal lines. 
slight decrease in the mean frequency of SSWs by $9 \%$ across all La Niña experiments. This result is inconsistent with the findings from some reanalysis studies that show an increase in SSW frequency under both El Niño and La Niña (Butler and Polvani 2011; Garfinkel et al. 2012; Butler et al. 2014; Polvani et al. 2017; Song and Son 2018; Domeisen et al. 2019). However, the number of ENSO events during the reanalysis era is relatively small compared to the large internal variability in the Arctic polar vortex and the change in frequency of SSWs under La Niña is sensitive to the reanalysis dataset used (Polvani et al. 2017).

\section{d. Temporal evolution of zonal mean wind anomalies}

Figure 9 shows the seasonal evolution of zonal mean zonal wind anomalies at $60^{\circ} \mathrm{N}$ as a function of pressure through boreal winter. The effect of the strongest El Niño perturbations (EN2.25 and EN3) on the extratropical lower stratospheric circulation is already evident in early winter. By midwinter there is a clear reduction in zonal wind speeds, which intensifies in the lower stratosphere in late winter and coincides with a reduction in westerlies in the troposphere and at the surface. The EN0.75 experiment shows a qualitatively similar pattern of wind anomalies to the larger El Niño perturbations, but these are smaller in amplitude and hence less statistically significant. Zhou et al. (2018) find in WACCM4 experiments that the largest stratospheric response to both strong and moderate El Niño occurs in late winter, whereas Fig. 9 shows the strongest response in our El Niño experiments occurs in January and February. This difference could potentially be due to the different seasonal evolution of the imposed El Niño forcing and/or differences in the climatological polar vortex characteristics in HadGEM3 and WACCM4.

While the broad pattern of extratropical circulation change from the stratosphere to the surface shown in Fig. 9 has been described in many previous studies (e.g., Christiansen 2001; Cagnazzo and Manzini 2009; Ineson and Scaife 2009), we show here that under increasing El Niño amplitude the strength of the wind anomalies increases monotonically. The response to EN3 is approximately double that in EN1.5, suggesting an approximately linear response over the range of El Niño forcing considered here (see also Fig. 7). Together Figs. 5, 8 , and 9 suggest an important role for the stratospheric pathway in determining the tropospheric circulation response to El Niño in our experiments.

For the La Niña experiments, there is no discernible stratospheric wind response in LN0.75 and LN1.5. For LN2.25 and LN3 there are significant increases in stratospheric winds, but these are smaller in magnitude than in the equivalent El Niño experiments and have a different temporal signature, with the largest stratospheric changes for La Niña occurring in NovemberDecember and late winter (March) rather than in midwinter for El Niño. Significant changes in tropospheric extratropical zonal winds only occur in LN3 in early spring, potentially suggesting a distinct mechanism for the remote teleconnection to La Niña compared to El Niño (Jiménez-Esteve and Domeisen 2018).

\section{e. Changes in the North Atlantic Oscillation}

Figure 10 shows the evolution of SLP anomalies in the experiments averaged over the Euro-Atlantic sector $\left(30^{\circ} \mathrm{W}-30^{\circ} \mathrm{E}\right)$ as a function of latitude and time. For all the La Niña experiments and the EN0.75 experiment there are virtually no significant changes in SLP in the EuroAtlantic sector, except for a small strengthening of the Azores high in early winter in LN2.25 and LN3. However, for El Niño amplitudes of $1.5 \mathrm{~K}$ and larger there is a clear SLP dipole pattern between December and February comprised of a weakening of the Icelandic low $\left(60^{\circ}-70^{\circ} \mathrm{N}\right)$ and a weakening of the Azores high $\left(30^{\circ}-50^{\circ} \mathrm{N}\right)$. The strongest anomalies are found in February, when in the EN3 experiment the Icelandic low and the Azores high become weaker by around 7 and $5 \mathrm{hPa}$, respectively. This corresponds to a more negative NAO index and a weakening of the North Atlantic eddy-driven jet (Figs. 5 and 9). The different timing in the Euro-Atlantic SLP response to El Niño and La Niña may suggest different dominant mechanisms for the teleconnections. While the stratospheric pathway appears to play an important role for the propagation of the El Niño signal to the EuroAtlantic sector, other mechanisms such as changes in tropospheric wave activity fluxes between the North Pacific and North Atlantic might be more important for the response to La Niña in these experiments.

Figure 11 shows a scatterplot of the DJF NAO index for each winter as a function of ENSO amplitude. Overall, there is an inverse relationship between the mean NAO index and ENSO amplitude. The strongest relationship is found in the top-left quadrant, where $75 \%$ of simulated El Niño winters coincide with a negative NAO index. In EN3, almost all winters have a negative NAO index with a mean anomaly of -1.65 standard deviations (s.d.). Across the four El Niño experiments, the mean DJF NAO anomaly increases as a function of Niño-3.4 amplitude at a rate of around -0.6 s.d. $\mathrm{K}^{-1}$. The experiments with the largest frequency of SSWs (Fig. 8) show a more negative NAO index in agreement with Charlton and Polvani (2007) and reinforces that the winter NAO intensity and sign have a strong dependence on the strength of the stratospheric polar vortex (Kidston et al. 2015; Scaife et al. 2016; Polvani et al. 2017). The relationship in the bottom-right quadrant of Fig. 11 is weaker, where $55 \%$ of simulated La Niña 
(a)

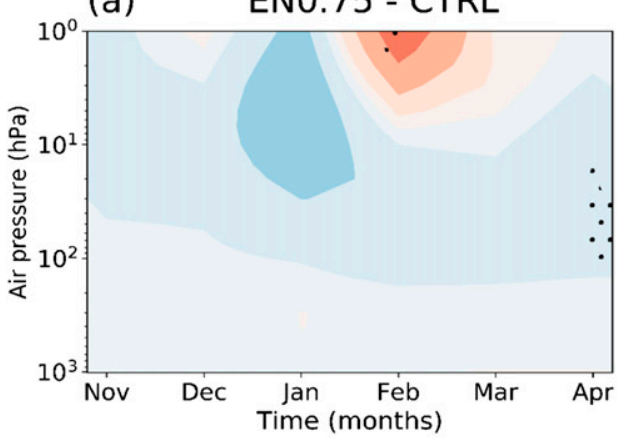

(c) $\quad$ EN1.5 - CTRL

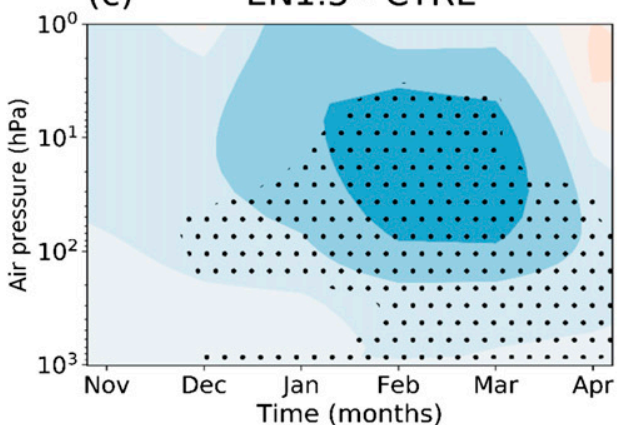

(e) $\quad$ EN2.25 - CTRL

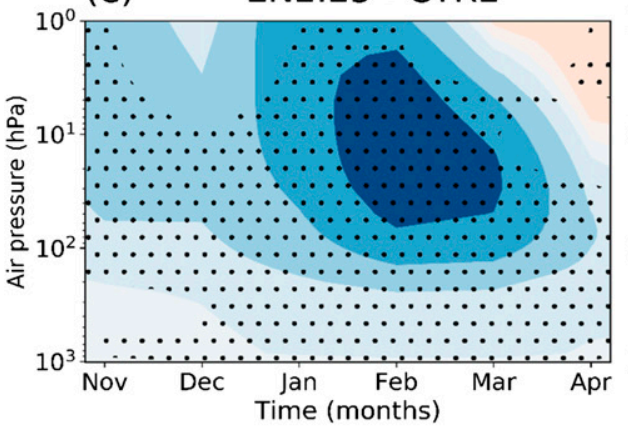

(g) EN3 - CTRL

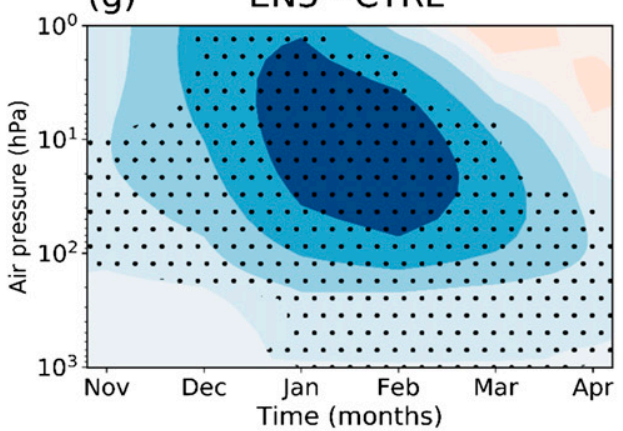

(b) $\quad$ LN0.75 - CTRL

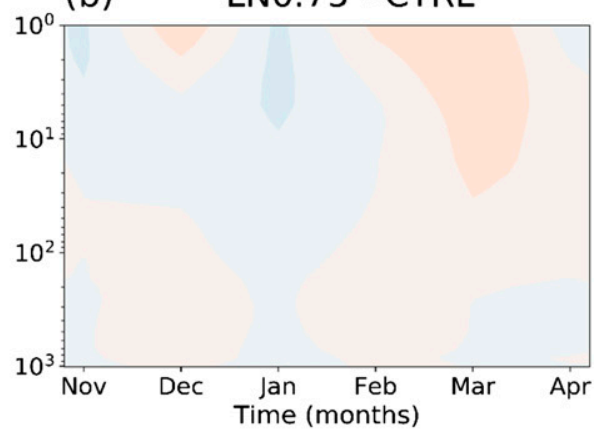

(d) $\quad$ LN1.5 - CTRL

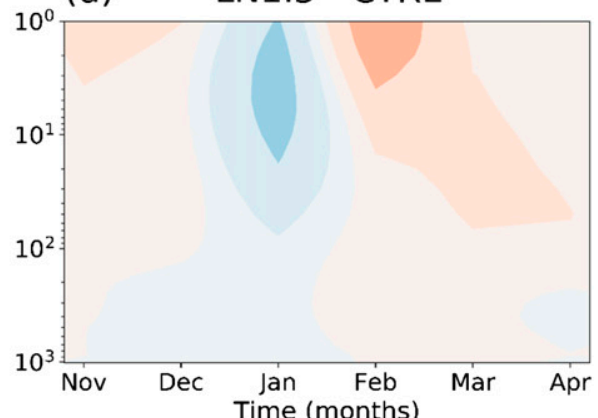

(f) $\quad$ LN2.25 - CTRL

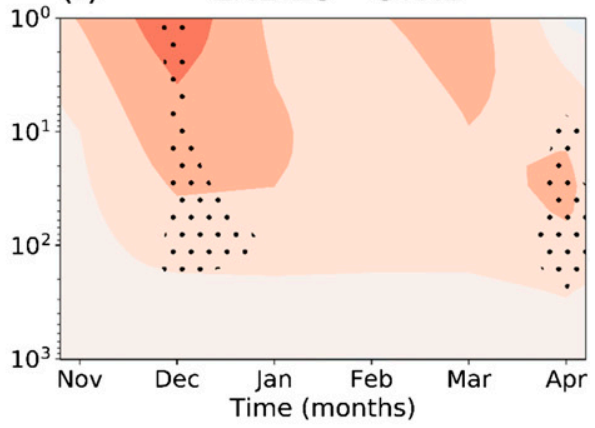

(h) $\quad$ LN3 - CTRL

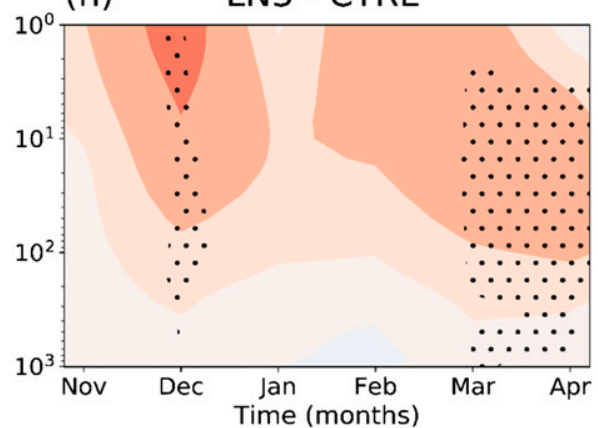

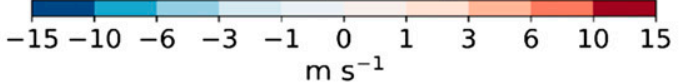

FIG. 9. Cross sections of zonal mean zonal wind anomalies $\left(\mathrm{m} \mathrm{s}^{-1}\right)$ at $60^{\circ} \mathrm{N}$ as a function of pressure and time. Zonal mean zonal wind response to (left) El Niño and (right) La Niña in (from top to bottom) crescent order of magnitude. Red (blue) colors show positive (negative) anomalies in zonal mean zonal wind $\left(\mathrm{m} \mathrm{s}^{-1}\right)$. Black stippling indicates statistical significance at the $95 \%$ confidence level. 
(a) EN0.75 - CTRL

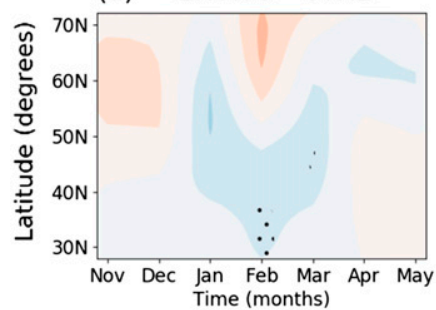

(e) LN0.75 - CTRL

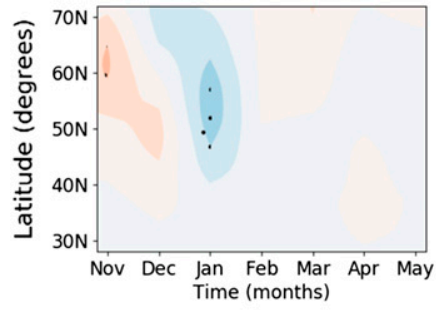

(b) EN1.5 - CTRL

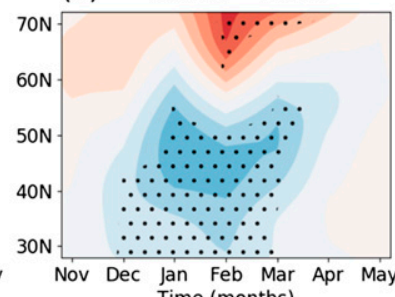

(f) $\quad$ LN1.5 - CTRL

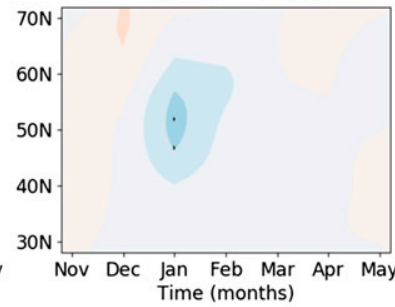

(c) EN2.25 - CTRL

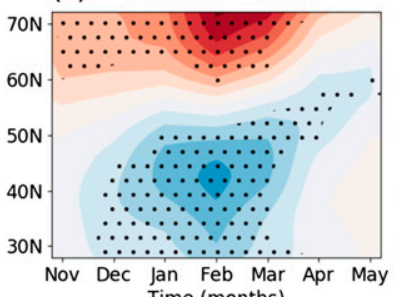

Time (months)

(g) LN2.25 - CTRL

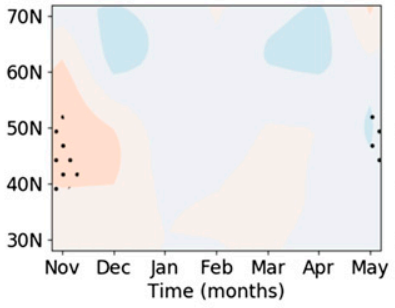

(d) EN3 - CTRL

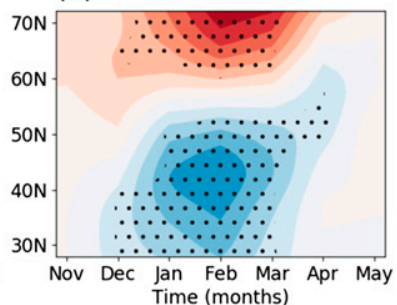

(h) LN3 - CTRL

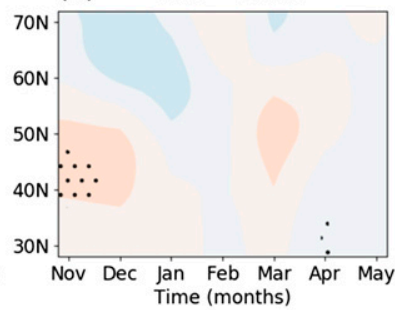

FIG. 10. Monthly evolution of SLP response in the European sector $\left(30^{\circ} \mathrm{W}-30^{\circ} \mathrm{E}\right.$ average) between $30^{\circ}$ and $70^{\circ} \mathrm{N}$. The two rows are in crescent order of magnitude of SST anomalies in the equatorial Pacific. Red (blue) colors show positive (negative) anomalies in sea level pressure (in hPa). Black stippling indicates significance at the $95 \%$ confidence level.

winters are associated with a positive NAO, which represents only a small shift in the NAO distribution compared to the control experiment. Only the strongest La Niña perturbations (LN2.25 and LN3) project weakly onto a positive NAO index (see also Fig. 10). As expected given the results described above, the top-right and bottom-left quadrants of Fig. 11 show weaker relationships with just $25 \%$ with ENSO+/NAO+ and $45 \%$ with ENSO-/ $\mathrm{NAO}-$.
With the results from Fig. 11 in mind, we return to the assessment of asymmetry in the response between ENSO phases introduced in section $3 \mathrm{a}$. Figures $3 \mathrm{a}$ and $3 \mathrm{~b}$ show that the SLP differences in the polar and Euro-Atlantic sectors are relatively larger for $2 \times(\mathrm{EN} 1.5+\mathrm{LN} 1.5)$ (12.5 and $7.5 \mathrm{hPa}$, respectively) than for the sum of the strongest perturbations EN3 + LN3 (10 and $5 \mathrm{hPa}$, respectively). For the nonlinearity of SLP response within each ENSO phase (Figs. 3c,d), the difference between

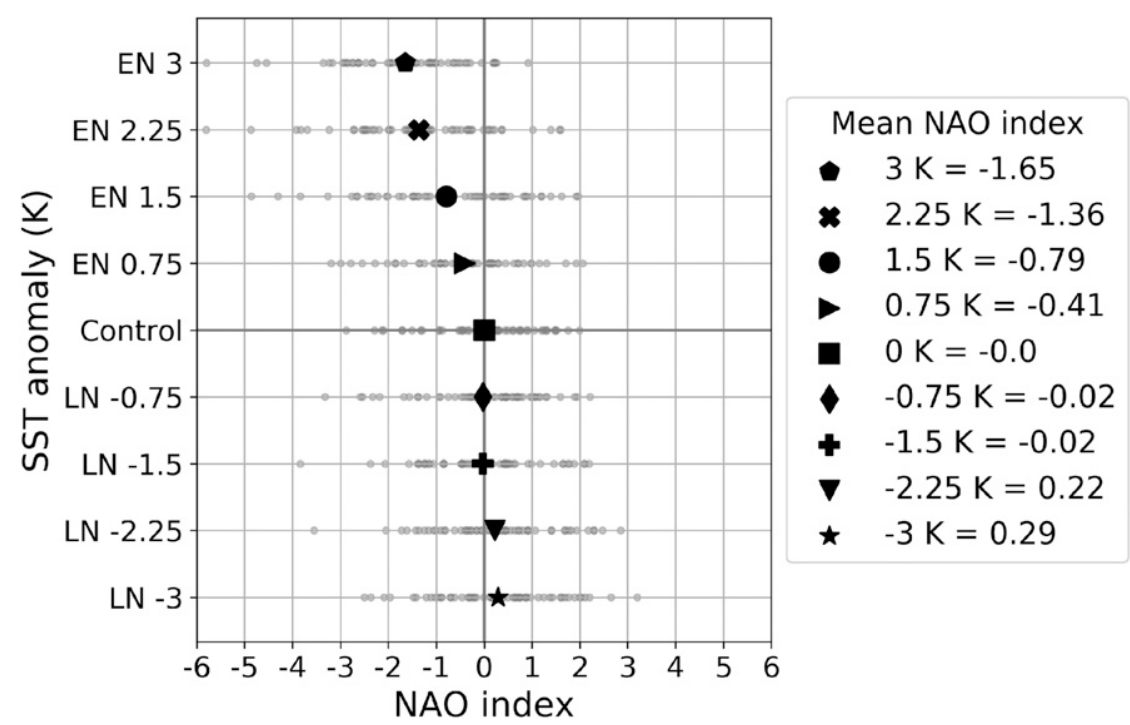

FIG. 11. Scatterplot of DJF NAO index as a function of ENSO magnitude. Each gray point represents one year and the black symbols show the 54-yr mean NAO index for each experiment. 
TABLE 1. Winter (DJF) averaged climate response to ENSO over the northern Europe (NEU) and Mediterranean basin (MED) regions. Precipitation is shown in $\mathrm{mm} \mathrm{day}^{-1}$, temperature at $850 \mathrm{hPa}$ in $\mathrm{K}$, and zonal wind at $1000 \mathrm{hPa} \mathrm{in} \mathrm{m} \mathrm{s}^{-1}$. Results in bold indicate statistical significance at the $95 \%$ confidence level.

\begin{tabular}{|c|c|c|c|c|}
\hline & $\begin{array}{c}\text { Perturbation } \\
\text { experiment }\end{array}$ & $\begin{array}{l}\text { Precipitation } \\
\left(\mathrm{mm} \mathrm{day}^{-1}\right)\end{array}$ & $\begin{array}{l}\text { Temperature } \\
850 \mathrm{hPa}(\mathrm{K})\end{array}$ & $\begin{array}{l}\text { Zonal wind } 1000 \\
\mathrm{hPa}\left(\mathrm{m} \mathrm{s}^{-1}\right)\end{array}$ \\
\hline \multirow{8}{*}{$\begin{array}{l}\text { Northern Europe } \\
\text { (NEU) }\end{array}$} & EN3 & -0.06 & -0.83 & -0.52 \\
\hline & EN2.25 & -0.1 & -0.67 & -0.62 \\
\hline & EN1.5 & -0.1 & -0.45 & -0.52 \\
\hline & EN0.75 & -0.02 & -0.19 & -0.09 \\
\hline & LN0.75 & 0.07 & -0.10 & -0.05 \\
\hline & LN1.5 & -0.01 & -0.19 & -0.16 \\
\hline & LN2.25 & 0.02 & 0.05 & -0.06 \\
\hline & LN3 & 0.04 & -0.14 & -0.05 \\
\hline \multirow{8}{*}{$\begin{array}{l}\text { Mediterranean region } \\
\quad(\text { MED) }\end{array}$} & EN3 & 0.31 & 0.59 & -0.04 \\
\hline & EN2.25 & 0.35 & 0.62 & -0.06 \\
\hline & EN1.5 & 0.24 & 0.66 & -0.03 \\
\hline & EN0.75 & 0.08 & 0.23 & -0.04 \\
\hline & LN0.75 & -0.02 & 0.28 & 0.04 \\
\hline & LN1.5 & 0.01 & 0.29 & 0.05 \\
\hline & LN2.25 & -0.09 & 0.11 & -0.03 \\
\hline & LN3 & -0.06 & 0.02 & 0.04 \\
\hline
\end{tabular}

EN3 and $2 \times$ EN1.5 in the Euro-Atlantic sector shows an anomalous ridge over the United Kingdom, which could be related to differences in blocking between the experiments and deviations from a typical NAO-like response (Graf and Funke 1986); however, a detailed assessment of blocking is beyond the scope of this study. Contrary to El Niño, the La Niña perturbations show weaker nonlinearities in SLP response (Fig. 3d), except in the North Atlantic where the strongest La Niña perturbation shows an anomalous ridge over the United Kingdom and southern Europe and a trough over Greenland and Iceland that projects onto a weak positive NAO pattern.

\section{f. European surface climate response}

Table 1 shows changes in regional mean DJF climate anomalies over the NEU and MED regions in the ENSO experiments (see section 2 for region definitions). The differences in all the La Niña perturbation experiments are not statistically significant at the $95 \%$ confidence level and are therefore not discussed. There is a negligible decrease in precipitation in the NEU region for EN3, whereas in the MED region there is a positive precipitation anomaly of up to $0.35 \mathrm{~mm} \mathrm{day}^{-1}$ in EN2.25. The changes in precipitation pattern result from the southward displacement of the North Atlantic eddy-driven jet along with the weakening of the Icelandic low and the Azores high (see section 3d). The jet is shifted to lower latitudes and favors enhanced heat and moisture transport over the Atlantic and across the south of Europe (not shown).
The negative and positive $850 \mathrm{hPa}$ temperature anomalies in the NEU and MED regions, respectively, are reminiscent of the canonical temperature pattern associated with a negative NAO (Hurrell et al. 2003); however, the differences in the experiments are not highly statistically significant. This may be related to the fact that the SSTs over the Atlantic basin are held fixed in these atmosphere-only experiments, and hence any changes in temperature associated with feedbacks on the ocean surface are neglected.

In agreement with Fig. 9, significant decreases in nearsurface zonal winds are found in the NEU region for EN1.5, $\mathrm{EN} 2.25$, and EN3, the largest decrease of $-0.62 \mathrm{~m} \mathrm{~s}^{-1}$ is found in EN2.25. Over the MED region, negative zonal wind anomalies do not surpass $-0.04 \mathrm{~m} \mathrm{~s}^{-1}$ in the strongest El Niño forcing and are not statistically significant.

\section{Discussion}

There have been numerous studies in the last decade using different approaches to assess the influence of ENSO on the occurrence of SSWs. Table 2 provides a meta-analysis of SSW frequencies for El Niño, La Niña, and ENSO neutral conditions found in these studies and compares them with the results of this study.

The relatively high frequency of SSWs in the ENSOneutral experiment $\left(0.8 \mathrm{yr}^{-1}\right)$ is consistent with an earlier version of HadGEM2, which showed a slightly higher SSW frequency than other high-top climate models (Charlton-Perez et al. 2013). Nevertheless, the increase in SSW frequency between ENSO neutral and El Niño years in HadGEM3 $\left(0.2 \mathrm{yr}^{-1}\right)$ is very consistent 
TABLE 2. Synthesis of SSW frequencies under El Niño, La Niña, and ENSO neutral conditions from various studies. The results from this study are calculated by averaging across all of the El Niño and La Niña perturbation amplitudes, while Neutral is calculated from the control experiment. (IGCM3 is version 3 of the Reading Intermediate General Circulation Model; CCMVal is SPARC ChemistryClimate Model Validation Activity; for other expansions, see http://www.ametsoc.org/PubsAcronymList.)

\begin{tabular}{|c|c|c|c|c|}
\hline Reference & Model/dataset & El Niño & La Niña & Neutral \\
\hline Bell et al. (2009) & IGCM3 model simulations & 0.55 & - & 0.42 \\
\hline Butler and Polvani (2011) & NCEP-NCAR reanalysis 1958-2010 & 0.72 & 0.78 & 0.41 \\
\hline Garfinkel et al. (2012) & $\begin{array}{l}\text { ERA-40 reanalysis } 1960-2004 \\
\text { GEOS CCM perpetual ENSO } 150 \text { winters } \\
\text { CCMVal model integrations } 1960-2004\end{array}$ & $\begin{array}{l}0.71 \\
0.70 \\
0.83\end{array}$ & $\begin{array}{l}0.73 \\
0.18 \\
0.60\end{array}$ & $\begin{array}{l}0.33 \\
0.32 \\
0.58\end{array}$ \\
\hline Li and Lau (2013) & 800-yr CM3 simulation & 0.28 & 0.23 & - \\
\hline Butler et al. (2014) & NCEP-NCAR reanalysis 1958-2013 & 0.79 & 0.72 & 0.37 \\
\hline Domeisen et al. (2015) & MPI-ESM seasonal prediction system & 0.63 & 0.46 & 0.48 \\
\hline Polvani et al. (2017) & $\begin{array}{l}\text { 46LCAM5 model simulations 1952-2003 } \\
\text { NCEP-NCAR reanalysis 1958-2013 } \\
\text { ERA-40-ERA-I reanalysis 1958-2013 }\end{array}$ & $\begin{array}{l}0.70 \\
0.80 \\
0.80\end{array}$ & $\begin{array}{l}0.51 \\
0.63 \\
0.63\end{array}$ & $\begin{array}{l}0.55 \\
0.45 \\
0.60\end{array}$ \\
\hline Calvo et al. (2017) & $\begin{array}{l}\text { CMIP5 high-top models (EP El Niño } \\
\text { only) 1951-2005 }\end{array}$ & 0.66 & - & 0.52 \\
\hline Song and Son (2018) & $\begin{array}{l}\text { NCEP-NCAR reanalysis (1958-2014) } \\
\text { JRA-55 Reanalysis (1958-2014) } \\
\text { CMIP5 models historical simulations } \\
\quad(1950-2005)\end{array}$ & $\begin{array}{l}0.81 \\
0.81 \\
0.59\end{array}$ & $\begin{array}{l}0.65 \\
0.70 \\
0.55\end{array}$ & $\begin{array}{l}0.43 \\
0.48 \\
0.56\end{array}$ \\
\hline Domeisen et al. (2019) & $\begin{array}{l}\text { JRA-55, ERA-40, ERA-Interim, NCEP- } \\
\text { NCAR, and MERRA2 reanalyses } \\
\text { (1958-2017) }\end{array}$ & 0.72 & 0.68 & 0.47 \\
\hline This study & HadGEM3 model simulations & 1.08 & 0.72 & 0.79 \\
\hline
\end{tabular}

with the increases found in the other studies ( 0.13 to $0.42 \mathrm{yr}^{-1}$; see Table 2). For La Niña, there is a clear distinction in findings between the studies using NCEPNCAR reanalysis dataset and other studies. The NCEPNCAR dataset shows higher SSW frequencies in La Niña years compared to ENSO neutral years. However, several studies using climate models [e.g., Domeisen et al. (2015) and Polvani et al. (2017), as well as this work] consistently show almost no change in SSW frequency in La Niña conditions compared to ENSO neutral. This could reflect either a deficiency of models to capture the effects of La Niña in the stratosphere or a biased sample for La Niña years from the relatively short reanalysis record. A noteworthy point is that the ERA-40/ERAInterim reanalysis dataset also analyzed by Polvani et al. (2017) shows little difference in SSW frequency in La Niña years, suggesting there are substantial differences in the apparent La Niña-SSW relationship between reanalyses. It should be noted that the experiments performed here are more idealized than many of the studies listed in Table 2. The SST perturbations in this study are based on an analytic function that captures the broad pattern of ENSO, whereas some other studies base their experiments on observed ENSO events.
The above discussion of the ENSO-SSW relationship is related to the proposed saturation of the stratospheric pathway under large El Niño forcing. The fact that the strongest negative NAO response occurs in our EN3 experiment disagrees with the work of Toniazzo and Scaife (2006), who found that the observed response to moderate El Niño events $(1.4 \mathrm{~K})$ projects onto a negative NAO, but the response to the strongest El Niño events $(\sim 2.8 \mathrm{~K})$ does not resemble a negative NAO. However, Toniazzo and Scaife (2006) were not able to reproduce this difference with an atmospheric model with a poorly resolved stratosphere, and the observed strongest El Niño events only reflected a few years and may therefore be affected by small sample size and other factors such as differences in SST pattern. More recently Hardiman et al. (2019) have shown using initialized seasonal hindcasts that the winter North Atlantic response during strong $\mathrm{El}$ Niños does not strongly resemble the NAO. However, the importance of initialization for this result is currently unclear, as the hindcast ensemble only samples a small number of observed strong El Niños. Rao and Ren (2016b) found a weaker stratospheric response under strong $(2 \mathrm{~K})$ versus moderate $(1 \mathrm{~K}) \mathrm{El}$ Niño forcing, despite also finding 
larger tropical latent heating anomalies for the strong El Niño perturbation. Bell et al. (2009) suggested that during strong El Niño events the stratospheric pathway becomes saturated owing to a natural limit to the dynamical warming of the polar vortex following SSWs. However, in their El Niño perturbation experiment the frequency of SSWs is only $0.55 \mathrm{yr}^{-1}$ (Table 2), whereas for our largest-amplitude EN3 experiment we find a mean SSW frequency of $1.28 \mathrm{yr}^{-1}$ with 17 out of 54 winters having two or more SSWs. Hence it would appear that with an El Niño amplitude of $3 \mathrm{~K}$ we do not reach a point where saturation of the stratospheric pathway occurs, despite HadGEM3 having an SSW frequency in the control experiment that is double that of the model used by Bell et al. (2009). It may therefore be a limitation of the model used by Bell et al. (2009), possibly associated with a coarser vertical resolution (26 levels compared to 85 in HadGEM3), that saturation of the stratospheric pathway was reached at a lower mean SSW frequency.

In contrast to Bell et al. (2009), Toniazzo and Scaife (2006), and Hardiman et al. (2019), we find that the negative NAO response becomes stronger as the $\mathrm{El}$ Niño forcing increases up to $3 \mathrm{~K}$ and that this is predominantly associated with the downward influence from the stratospheric pathway. Other studies have separated ENSO years with and without SSWs to isolate the stratospheric and the tropospheric pathways (e.g., Butler et al. 2014; Domeisen et al. 2015); however, in this case one must take care to define an appropriate reference state for calculating the NAO index that avoids biasing the sample. Given that in the EN1.5, EN2.25, and EN3 experiments the majority of the years $(>85 \%)$ have at least one SSW, we cannot perform such a separation and retain adequate sample sizes to isolate a signal from internal variability.

Figure 3 emphasizes that although symmetric SST anomalies are imposed to simulate El Niño and La Niña perturbations the climate response is strongly asymmetric between both phases. The asymmetries between El Niño and La Niña in the stratosphere and North Atlantic can be at least partly traced back to the changes in convection and Rossby wave source anomalies. Our experiments capture the threshold behavior for the relationship between OLR and SSTs in the east Pacific found by Johnson and Kosaka (2016) (see Fig. S2), which reflects that negative SST anomalies in the east Pacific cold tongue are less effective at perturbing tropical convection (Xie et al. 2018). Jiménez-Esteve and Domeisen (2019) also found that nonlinearities and asymmetries in the response to ENSO in the North $\mathrm{Pa}$ cific depend on the magnitude of the ENSO event rather than on the spatial location of the SST perturbations.
Conversely, Garfinkel et al. (2018) suggest an influence of the spatial location of SST perturbations and tropical convection on the linearity of responses between ENSO phases. Rao and Ren (2016b) found a stronger response for a $2 \mathrm{~K}$ La Niña compared to a $1 \mathrm{~K}$ perturbation, but the tropical latent heating response did not increase markedly upon doubling La Niña amplitude, so it is unclear what mechanism could explain the larger stratospheric response. Sensitivities to background state and details of SST patterns may explain differences in the response to La Niña between various studies (Rao and Ren 2016b; Jiménez-Esteve and Domeisen 2019; Hardiman et al. 2019; this study).

The fact that the imposed La Niña SST anomalies in this study differ from some observed events in terms of spatial location and magnitude could influence the response in the tropical Pacific and subsequent teleconnection to high latitudes.

The experimental design implemented in this study neglects other indirect pathways for ENSO to influence the Euro-Atlantic region, for example through interactions with Atlantic sea surface temperatures (Cassou and Terray 2001) as a consequence of the use of an atmosphere-only model. However, a key advantage of our approach is that it allows the effect of ENSO amplitude to be cleanly separated from other factors such as the pattern of SST anomalies and external drivers of climate variability, which affect interpretation of the observational record.

\section{Conclusions}

This study has investigated the effect of variations in ENSO amplitude on European winter climate. A suite of idealized experiments was performed using the HadGEM3 model with imposed SST perturbations in the Niño-3.4 region of between $-3 \mathrm{~K}$ and $+3 \mathrm{~K}$. The imposed SSTs have an idealized spatial pattern representative of a classical east Pacific ENSO event (Fig. 1).

The imposed El Niño perturbations enhance deep convection in the equatorial Pacific, exciting an anomalous poleward propagating Rossby wave train that strengthens the Aleutian low and shifts its center toward North America. Oppositely signed, but substantially weaker, North Pacific anomalies are found for the equivalent amplitude La Niña perturbations. The Aleutian low acts as an atmospheric bridge between the troposphere and the stratosphere (Garfinkel et al. 2010); the El Niño perturbations enhance the vertical propagation of wave activity from the troposphere to the stratosphere, while only the strongest La Niña perturbations $(-2.25$ and $-3 \mathrm{~K})$ affect the stratospheric EP 
fluxes by inhibiting the upward wave propagation to the stratosphere.

As a consequence of the enhanced wave forcing under El Niño perturbations, the stratospheric polar vortex weakens throughout winter and the frequency of sudden stratospheric warmings increases by up to $\sim 60 \%$ under a $3 \mathrm{~K}$ El Niño perturbation. The weakening of the stratospheric polar vortex and the increase in frequency of SSWs increases monotonically across the range of $\mathrm{El}$ Niño amplitudes considered $(0.75,1.5,2.25$, and $3 \mathrm{~K})$. We therefore do not find evidence of a saturation of the stratospheric pathway for strong El Niño forcing as proposed by some studies (Toniazzo and Scaife 2006; Bell et al. 2009). Nevertheless, further investigation is necessary to determine at what forcing level saturation of the stratospheric pathway may occur. In the EN3 experiment, around $60 \%$ of winters have $1 \mathrm{SSW}, 27 \%$ have 2 SSWs, and only $7 \%$ have no SSWs, suggesting that saturation could occur for higher forcing amplitudes. In contrast, there are no substantive changes in SSW frequency in the La Niña experiments and the stratospheric winds only show significant strengthening in early and late winter for the strongest La Niña perturbations $(-2.25$ and $-3 \mathrm{~K})$.

At the surface over the Euro-Atlantic sector, the wintertime response to all four El Niño amplitudes projects onto a negative NAO pattern, with the largest SLP anomalies found in February. The winter mean NAO index anomaly increases monotonically with El Niño amplitude reaching -1.65 s.d. for the $3 \mathrm{~K}$ perturbation. The negative NAO conditions lead to drier winters over northern Eurasia and wetter winters in the Mediterranean. In contrast, the La Niña perturbations are associated with substantially smaller surface climate anomalies in the Euro-Atlantic sector that lack statistical significance, with only the -2.25 and $-3 \mathrm{~K}$ La Niña perturbations showing a weak response that projects onto the positive phase of the NAO. The substantially weaker response to La Niña compared to El Niño in these experiments may be partly related to the particular pattern of imposed SSTs, with tropical convection being potentially more sensitive to La Niña events that peak in the central and western Pacific.

This work confirms the importance of the stratosphere in the ENSO teleconnection to Europe in winter. Further research is needed to elucidate the mechanism for the timing of the La Niña teleconnection to Europe, which is only evident in early and late winter in the experiments described here and not in midwinter as indicated by reanalysis data (Jiménez-Esteve and Domeisen 2018). By systematically investigating the Euro-Atlantic response to different ENSO amplitudes over a large range of amplitudes from $-3 \mathrm{~K}$ to $+3 \mathrm{~K}$, this work has overcome some of the limitations of the typically small sample sizes of reanalyses and observation-based studies, highlighting the strong asymmetry between the climate response to El Niño and La Niña and a nonlinear behavior of different magnitude events of the same ENSO phase. A similar approach could be used to isolate the effect of variations in the spatial pattern of Pacific SST anomalies on the ENSO teleconnection to Europe.

Acknowledgments. We thank three anonymous reviewers for their constructive comments that helped to improve this paper. The Natural Environment Research Council supported ACM (Grant NE/M018199/1), YYSY (Grant NE/K004921/1), and JKF (NE/L013843/1). The authors thank Jorge Luis García Franco for technical assistance and Adam Scaife and Steven Hardiman for useful discussions.

\section{REFERENCES}

Ayarzagüena, B., S. Ineson, N. J. Dunstone, M. P. Baldwin, and A. A. Scaife, 2018: Intraseasonal effects of El Niño-Southern Oscillation on North Atlantic climate. J. Climate, 31, 88618873, https://doi.org/10.1175/JCLI-D-18-0097.1.

—, J. López-Parages, M. Iza, N. Calvo, and B. RodríguezFonseca, 2019: Stratospheric role in interdecadal changes of El Niño impacts over Europe. Climate Dyn., 52, 1173-1186, https://doi.org/10.1007/s00382-018-4186-3.

Barriopedro, D., and N. Calvo, 2014: On the relationship between ENSO, stratospheric sudden warmings, and blocking. J. Climate, 27, 4704-4720, https://doi.org/10.1175/JCLI-D-13-00770.1.

Bayr, T., D. I. V. Domeisen, and C. Wengel, 2019: The effect of the equatorial Pacific cold SST bias on simulated ENSO teleconnections to the North Pacific and California. Climate Dyn., https://doi.org/10.1007/S00382-019-04746-9.

Bell, C. J., L. J. Gray, A. J. Charlton-Perez, M. M. Joshi, and A. A. Scaife, 2009: Stratospheric communication of El Niño teleconnections to European winter. J. Climate, 22, 4083-4096, https://doi.org/10.1175/2009JCLI2717.1.

Butler, A. H., and L. M. Polvani, 2011: El Niño, La Niña, and stratospheric sudden warmings: A reevaluation in light of the observational record. Geophys. Res. Lett., 38, L13807, https:// doi.org/10.1029/2011GL048084.

,-- , and C. Deser, 2014: Separating the stratospheric and tropospheric pathways of El Niño-Southern Oscillation teleconnections. Environ. Res. Lett., 9, 024014, https://doi.org/ 10.1088/1748-9326/9/2/024014.

Cagnazzo, C., and E. Manzini, 2009: Impact of the stratosphere on the winter tropospheric teleconnections between ENSO and the North Atlantic and European region. J. Climate, 22, 1223 1238, https://doi.org/10.1175/2008JCLI2549.1.

Calvo, N., and Coauthors, 2017: Northern Hemisphere stratospheric pathway of different El Niño flavors in stratosphereresolving CMIP5 models. J. Climate, 30, 4351-4371, https:// doi.org/10.1175/JCLI-D-16-0132.1.

Capotondi, A., and Coauthors, 2015: Understanding ENSO diversity. Bull. Amer. Meteor. Soc., 96, 921-938, https://doi.org/ 10.1175/BAMS-D-13-00117.1. 
Cassou, C., and L. Terray, 2001: Dual influence of Atlantic and Pacific SST anomalies on the North Atlantic/Europe winter climate. Geophys. Res. Lett., 28, 3195-3198, https://doi.org/ 10.1029/2000GL012510.

Charlton, A. J., and L. M. Polvani, 2007: A new look at stratospheric sudden warmings. Part I: Climatology and modeling benchmarks. J. Climate, 20, 449-469, https://doi.org/10.1175/ JCLI3996.1.

Charlton-Perez, A. J., and Coauthors, 2013: On the lack of stratospheric dynamical variability in low-top versions of the CMIP5 models. J. Geophys. Res. Atmos., 118, 2494-2505, https://doi.org/10.1002/jgrd.50125.

Christiansen, B., 2001: Downward propagation of zonal mean zonal wind anomalies from the stratosphere to the troposphere: Model and reanalysis. J. Geophys. Res. Atmos., 106, 27 307-27 322, https://doi.org/10.1029/2000JD000214.

Dee, D. P., and Coauthors, 2011: The ERA-Interim reanalysis: Configuration and performance of the data assimilation system. Quart. J. Roy. Meteor. Soc., 137, 553-597, https://doi.org/ 10.1002/qj.828.

Diaz, H. F., M. Hoerling, and J. K. Eischeid, 2001: ENSO variability, teleconnections and climate change. Int. J. Climatol., 21, 1845-1862, https://doi.org/10.1002/joc.631.

Domeisen, D. I. V., A. H. Butler, K. Frohlich, M. Bittner, W. A. Müller, and J. Baehr, 2015: Seasonal predictability over Europe arising from El Niño and stratospheric variability in the MPI-ESM seasonal prediction system. J. Climate, 28, 256-271, https://doi.org/10.1175/JCLI-D-14-00207.1.

_ C. I. Garfinkel, and A. H. Butler, 2019: The teleconnection of El Niño Southern Oscillation to the stratosphere. Rev. Geophys., 57, 5-47, https://doi.org/10.1029/2018RG000596.

Edmon, H., B. J. Hoskins, and M. E. McIntyre, 1980: EliassenPalm cross sections for the troposphere. J. Atmos. Sci., 37, 2600-2616, https://doi.org/10.1175/1520-0469(1980)037<2600: EPCSFT $>2.0 . \mathrm{CO} ; 2$.

Garfinkel, C., and D. L. Hartmann, 2008: Different ENSO teleconnections and their effects on the stratospheric polar vortex. J. Geophys. Res., 113, D18114, https://doi.org/10.1029/ 2008JD009920.

- - - and F. Sassi, 2010: Tropospheric precursors of anomalous Northern Hemisphere stratospheric polar vortices. J. Climate, 23, 3282-3299, https://doi.org/10.1175/2010JCLI3010.1.

- , A. H. Butler, D. W. Waugh, M. M. Hurwitz, and L. M. Polvani, 2012: Why might stratospheric sudden warmings occur with similar frequency in El Niño and La Niña winters? J. Geophys. Res., 117, D19106, https://doi.org/10.1029/2012JD017777.

_, I. Weinberger, I. P. White, L. D. Oman, V. Aquila, and Y. K. Lim, 2018: The salience of nonlinearities in the boreal winter response to ENSO: North Pacific and North America. Climate Dyn., 52, 4429-4446, https://doi.org/10.1007/S00382-018-4386-X.

Giorgi, F., and R. Francisco, 2000: Uncertainties in regional climate change prediction: A regional analysis of ensemble simulations with the HADCM2 coupled AOGCM. Climate Dyn., 16, 169-182, https://doi.org/10.1007/PL00013733.

Graf, H.-F., and H. Funke, 1986: Blockierungssituationen im europäisch-atlantischen Raum, Teil 1: Phänomenologische Untersuchungen. Z. Meteor., 36, 104-112.

Graham, N. E., and T. P. Barnett, 1987: Sea surface temperature, surface wind divergence, and convection over tropical oceans. Science, 238, 657-659, https://doi.org/10.1126/ science.238.4827.657.

Hardiman, S. C., N. Butchart, T. J. Hinton, S. M. Osprey, and L. J. Gray, 2012: The effect of a well-resolved stratosphere on surface climate: Differences between CMIP5 simulations with high and low top versions of the Met Office climate model. J. Climate, 25, 7083-7099, https://doi.org/10.1175/JCLI-D-11-00579.1.

—, N. J. Dunstone, A. A. Scaife, D. M. Smith, S. Ineson, J. Lim, and D. Fereday, 2019: The impact of strong El Niño and La Niña events on the North Atlantic. Geophys. Res. Lett., 46, 2874-2883, https://doi.org/10.1029/2018GL081776.

Hitchcock, P., and I. R. Simpson, 2014: The downward influence of stratospheric sudden warmings. J. Atmos. Sci., 71, 3856-3876, https://doi.org/10.1175/JAS-D-14-0012.1.

Hoerling, M. P., A. Kumar, and M. Zhong, 1997: El Niño, La Niña, and the nonlinearity of their teleconnections. J. Climate, 10, 1769-1786, https://doi.org/10.1175/1520-0442(1997)010<1769: ENOLNA $>2.0 . \mathrm{CO} ; 2$.

Hoskins, B. J., and D. J. Karoly, 1981: The steady linear response of a spherical atmosphere to thermal and orographic forcing. J. Atmos. Sci., 38, 1179-1196, https://doi.org/10.1175/15200469(1981)038<1179:TSLROA > 2.0.CO;2.

Hurrell, J. W., 1995: Decadal trends in the North Atlantic Oscillation: Regional temperatures and precipitation. Science, 269, 676-679, https://doi.org/10.1126/science.269.5224.676.

—, Y. Kushnir, G. Ottersen, and M. Visbeck, 2003: An overview of the North Atlantic oscillation. The North Atlantic Oscillation: Climatic Significance and Environmental Impact, Geophys. Monogr., Vol. 134, Amer. Geophys. Union, 1-35, https://doi.org/10.1029/134GM01.

Hurwitz, M. M., N. Calvo, C. I. Garfinkel, A. H. Butler, S. Ineson, C. Cagnazzo, E. Manzini, and C. Peña-Ortiz, 2014: Extratropical atmospheric response to ENSO in the CMIP5 models. Climate Dyn., 43, 3367-3376, https://doi.org/10.1007/s00382014-2110-z.

Ineson, S., and A. A. Scaife, 2009: The role of the stratosphere in the European climate response to El Niño. Nat. Geosci., 2, 3236, https://doi.org/10.1038/ngeo381.

Iza, M., N. Calvo, and E. Manzini, 2016: The stratospheric pathway of La Niña. J. Climate, 29, 8899-8914, https://doi.org/10.1175/ JCLI-D-16-0230.1.

Jiménez-Esteve, B., and D. I. V. Domeisen, 2018: The tropospheric pathway of the ENSO-North Atlantic teleconnection. J. Climate, 31, 4563-4584, https://doi.org/10.1175/JCLI-D-17-0716.1.

, and - 2019: Nonlinearity in the North Pacific atmospheric response to a linear ENSO forcing. Geophys. Res. Lett., 46, 2271-2281, https://doi.org/10.1029/2018GL081226.

Johnson, N. C., and Y. Kosaka, 2016: The impact of eastern equatorial Pacific convection on the diversity of boreal winter El Niño teleconnection patterns. Climate Dyn., 47, 3737-3765, https://doi.org/10.1007/S00382-016-3039-1.

Kidston, J., A. A. Scaife, S. C. Hardiman, D. M. Mitchell, N. Butchart, M. P. Baldwin, and L. J. Gray, 2015: Stratospheric influence on tropospheric jet streams, storm tracks and surface weather. Nat. Geosci., 8, 433-440, https://doi.org/10.1038/ngeo2424.

Larkin, N. K., and D. E. Harrison, 2005: Global seasonal temperature and precipitation anomalies during El Niño autumn and winter. Geophys. Res. Lett., 32, L16705, https://doi.org/ 10.1029/2005GL022860.

Li, Y., and N.-C. Lau, 2012: Impact of ENSO on the atmospheric variability over the North Atlantic in late winter-Role of transient eddies. J. Climate, 25, 320-342, https://doi.org/ 10.1175/JCLI-D-11-00037.1.

, and - 2013: Influences of ENSO on stratospheric variability, and the descent of stratospheric perturbations into the lower troposphere. J. Climate, 26, 4725-4748, https://doi.org/ 10.1175/JCLI-D-12-00581.1. 
Manzini, E., M. Giorgetta, M. Esch, L. Kornblueh, and E. Roeckner, 2006: The influence of sea surface temperatures on the northern winter stratosphere: Ensemble simulations with the MAECHAM5 model. J. Climate, 19, 3863-3881, https://doi.org/10.1175/JCLI3826.1.

Maycock, A. C., and P. Hitchcock, 2015: Do split and displacement sudden stratospheric warmings have different annular mode signatures? Geophys. Res. Lett., 42, 10 943-10 951, https:// doi.org/10.1002/2015GL066754.

Mizielinski, M. S., and Coauthors, 2014: High-resolution global climate modelling: The UPSCALE project, a large-simulation campaign. Geosci. Model Dev., 7, 1629-1640, https://doi.org/ 10.5194/gmd-7-1629-2014.

Müller, W. A., and E. Roeckner, 2006: ENSO impact on midlatitude circulation patterns in future climate change projections. Geophys. Res. Lett., 33, L05711, https://doi.org/ 10.1029/2005GL025032.

Niebauer, H. J., 1988: Effects of El Niño-Southern Oscillation and North Pacific weather patterns on interannual variability in the subarctic Bering Sea. J. Geophys. Res., 93, 5051-5068, https://doi.org/10.1029/JC093iC05p05051.

Osprey, S. M., L. J. Gray, S. C. Hardiman, N. Butchart, and T. J. Hinton, 2013: Stratospheric variability in 20th century CMIP5 simulations of the Met Office climate model: High-top versus low-top. J. Climate, 26, 1595-1606, https://doi.org/10.1175/ JCLI-D-12-00147.1.

Polvani, L. M., L. Sun, A. H. Butler, J. H. Richter, and C. Deser, 2017: Distinguishing stratospheric sudden warmings from ENSO as key drivers of wintertime climate variability over the North Atlantic and Eurasia. J. Climate, 30, 1959-1969, https:// doi.org/10.1175/JCLI-D-16-0277.1.

Rao, J., and R. Ren, 2016a: Asymmetry and nonlinearity of the influence of ENSO on the northern winter stratosphere: 1. Observations. J. Geophys. Res. Atmos., 121, 9000-9016, https://doi.org/10.1002/2015JD024520.

$\longrightarrow$, and $-2016 \mathrm{~b}$ : Asymmetry and nonlinearity of the influence of ENSO on the northern winter stratosphere: 2. Model study with WACCM. J. Geophys. Res. Atmos., 121, 9017-9032, https://doi.org/10.1002/2015JD024521.

Rayner, N. A., D. E. Parker, E. B. Horton, C. K. Folland, L. V. Alexander, D. P. Rowell, E. C. Kent, and A. Kaplan, 2003: Global analyses of sea surface temperature, sea ice, and night marine air temperature since the late nineteenth century. J. Geophys. Res., 108, 4407, https://doi.org/10.1029/2002JD002670.

Rodionov, S. N., J. Overland, and N. Bond, 2005: The Aleutian low and winter climatic conditions in the Bering Sea. Part I: Classification. J. Climate, 18, 160-177, https://doi.org/10.1175/ JCLI3253.1.

Rodríguez-Fonseca, B., and Coauthors, 2016: A review of ENSO influence on the North Atlantic. A non-stationary signal. Atmosphere, 7, 87, https://doi.org/10.3390/atmos7070087.
Sardeshmukh, P. D., and B. J. Hoskins, 1988: The generation of global rotational flow by steady idealized tropical divergence. J. Atmos. Sci., 45, 1228-1251, https://doi.org/10.1175/15200469(1988)045<1228:TGOGRF > 2.0.CO;2.

Scaife, A. A., and Coauthors, 2016: Seasonal winter forecasts and the stratosphere. Atmos. Sci. Lett., 17, 51-56, https://doi.org/ 10.1002/asl.598.

Song, K., and S. W. Son, 2018: Revisiting the ENSO-SSW relationship. J. Climate, 31, 2133-2143, https://doi.org/10.1175/ JCLI-D-17-0078.1.

Taguchi, M., and D. L. Hartmann, 2005: Interference of extratropical surface climate anomalies induced by El Niño and stratospheric sudden warmings. Geophys. Res. Lett., 32 , L04709, https://doi.org/10.1029/2004GL022004.

Toniazzo, T., and A. A. Scaife, 2006: The influence of ENSO on winter North Atlantic climate. Geophys. Res. Lett., 33, L24704, https://doi.org/10.1029/2006GL027881.

Visbeck, M. H., J. W. Hurrell, L. Polvani, and H. M. Cullen, 2001: The North Atlantic Oscillation: Past, present, and future. Proc. Natl. Acad. Sci. USA, 98, 12 876-12 877, https://doi.org/ 10.1073/pnas.231391598.

Waliser, D. E., and N. E. Graham, 1993: Convective cloud systems and warm-pool sea surface temperatures: Coupled interactions and self-regulation. J. Geophys. Res., 98, 12 881-12 893, https:// doi.org/10.1029/93JD00872.

Weinberger, I., C. I. Garfinkel, I. P. White, and L. Oman, 2019: The salience of nonlinearities in the boreal winter response to ENSO: Arctic stratosphere and Europe. Climate Dyn., https:// doi.org/10.1007/s00382-019-04805-1.

Xie, F., X. Zhou, J. Li, C. Sun, J. Feng, and X. Ma, 2018: The key role of background sea surface temperature over the cold tongue in asymmetric responses of the Arctic stratosphere to El Niño-Southern Oscillation. Environ. Res. Lett., 13, 114007, https://doi.org/10.1088/1748-9326/ aae 79b.

Yiu, Y. Y. C., and A.C. Maycock, 2019: On the seasonality of the El Niño teleconnection to the Amundsen Sea region. $J$. Climate, 32, 4829-4845, https://doi.org/10.1175/JCLI-D-180813.1.

Zhang, C., 1993: Large-scale variability of atmospheric deep convection in relation to sea surface temperature in the tropics. J. Climate, 6, 1898-1913, https://doi.org/10.1175/ 1520-0442(1993)006<1898:LSVOAD>2.0.CO;2.

Zhou, X., J. Li, F. Xie, Q. Chen, R. Ding, W. Zhang, and Y. Li, 2018: Does extreme El Niño have a different effect on the stratosphere in boreal winter than its moderate counterpart? J. Geophys. Res. Atmos., 123, 3071-3086, https://doi.org/ 10.1002/2017JD028064. 